J. Product. \& Dev., 24(2): $407-431$ (2019)

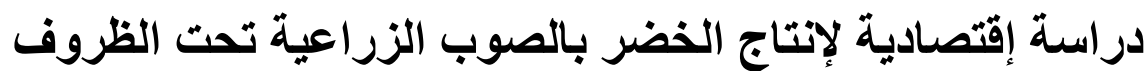

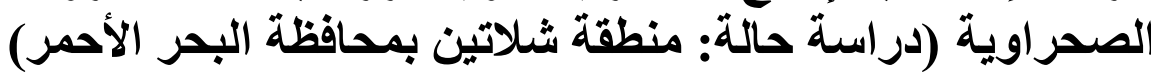

محمد على عواد أبو النجا ـ نادية محمود مهدي عبد المحسن

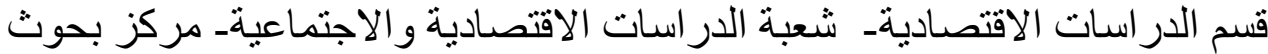

الصحر اء - مصر الصنا

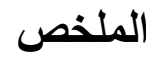

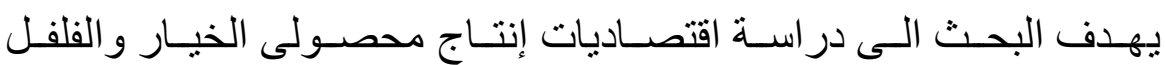

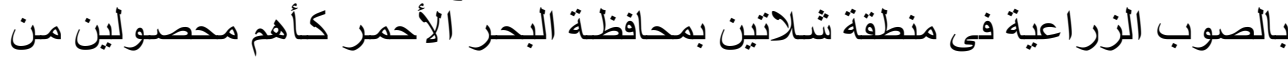

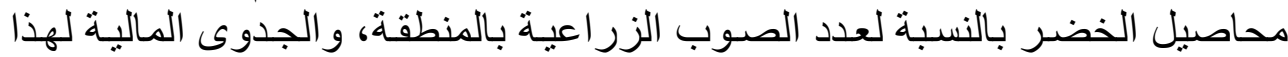

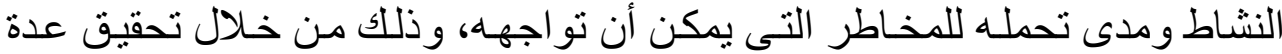

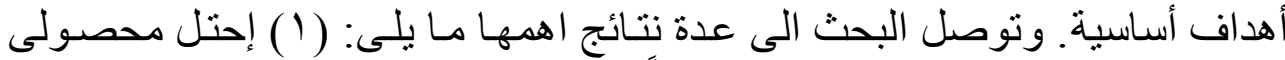

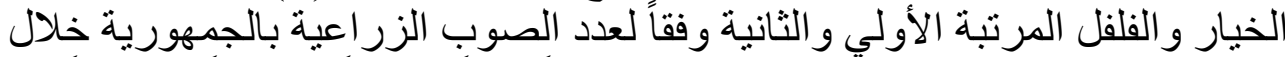

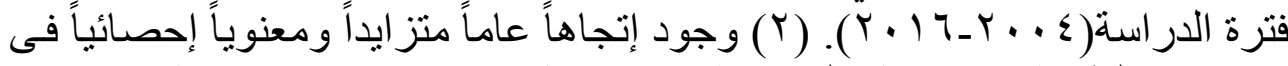

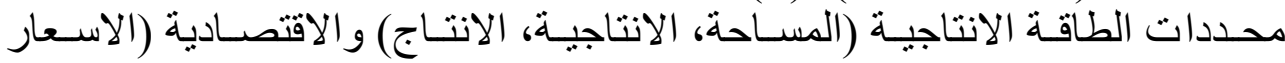

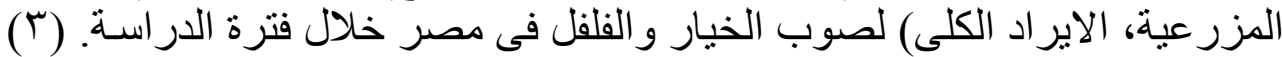

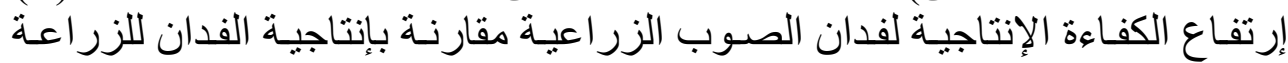

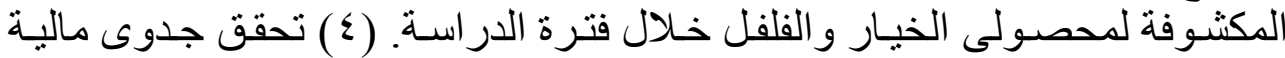

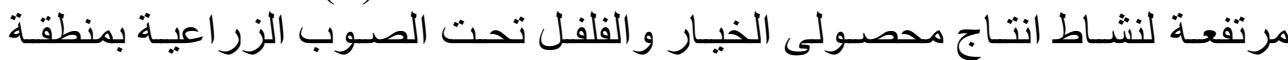

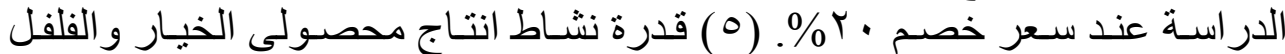

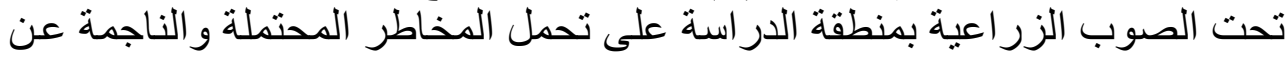

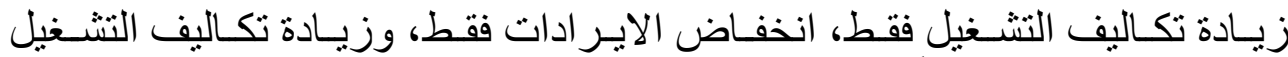

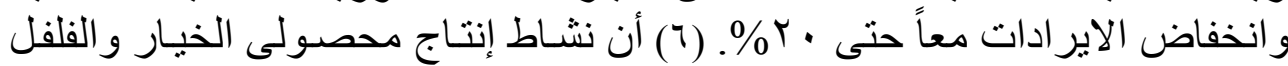

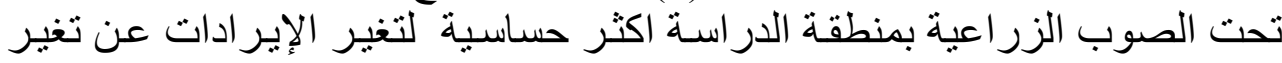

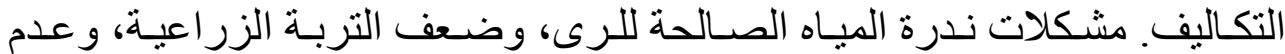

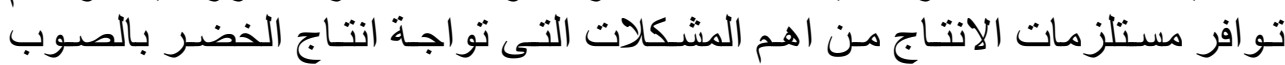

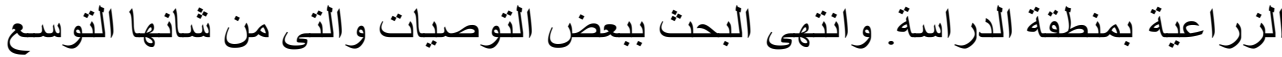

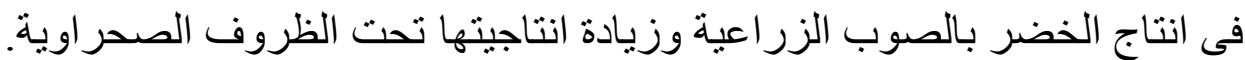

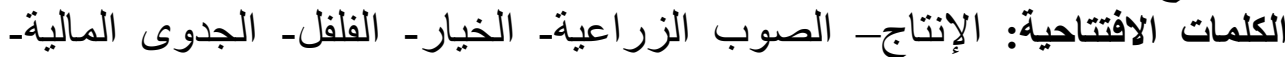

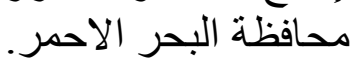

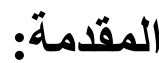

تعد قضية توفير الغذاء من أهم القضايا الإستر اتيجية التي تأخذ إهتمامـاً كبير اً

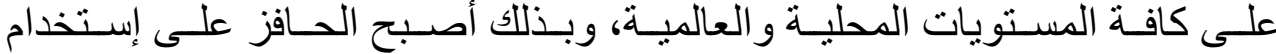




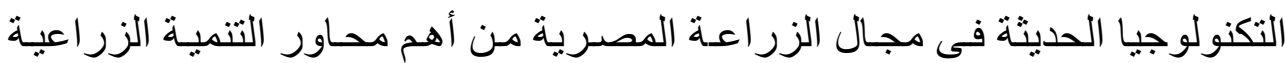

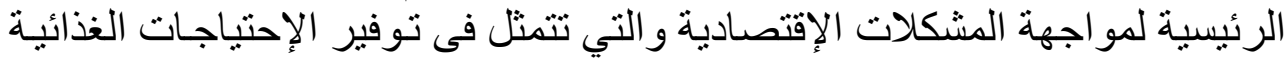

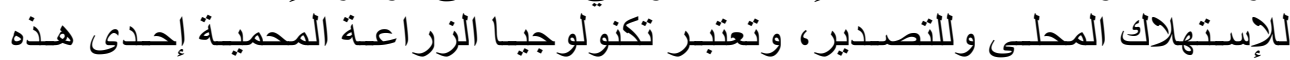

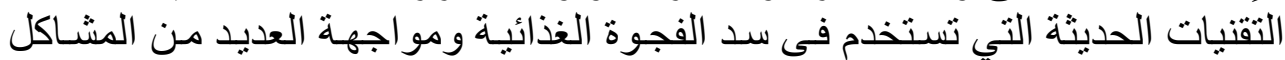

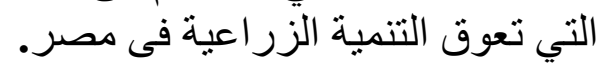

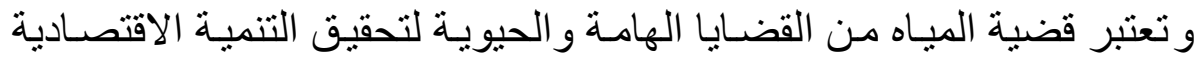

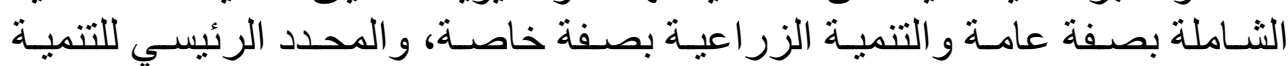

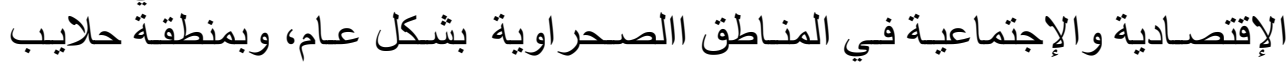

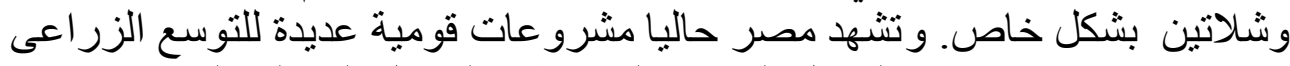

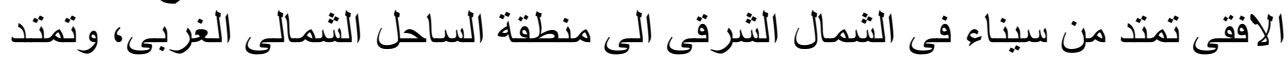

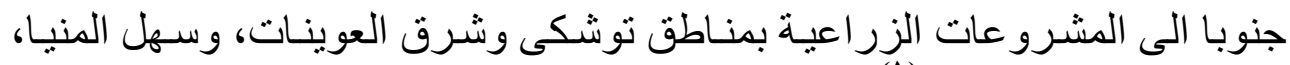
ومنطقة حلايب وشلاتين المنين (')

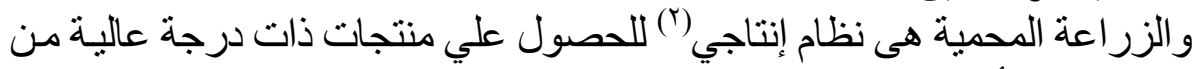

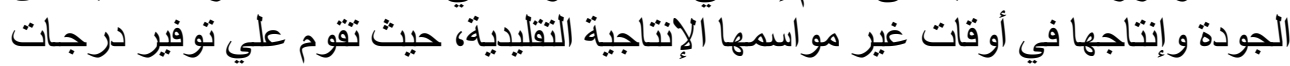

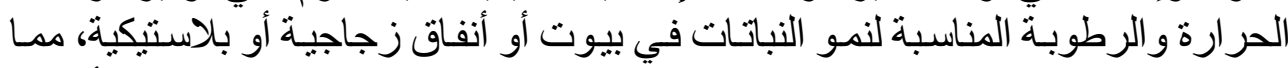

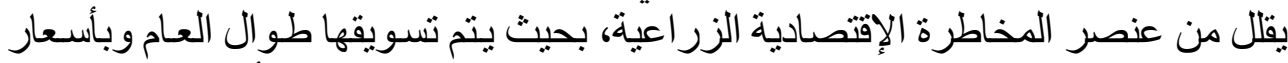

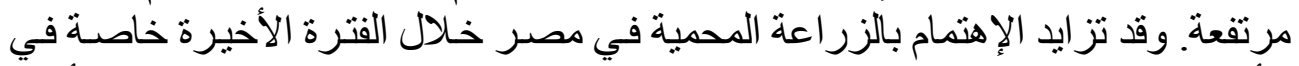

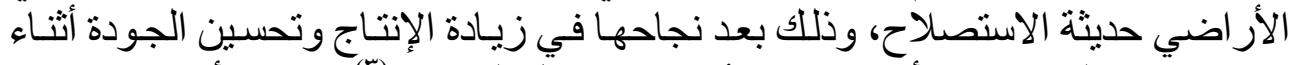

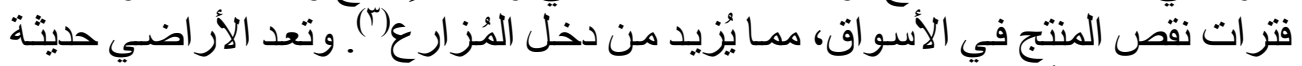

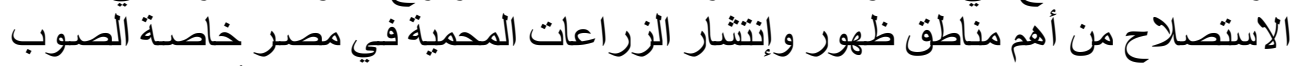

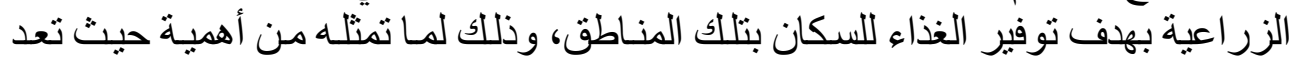

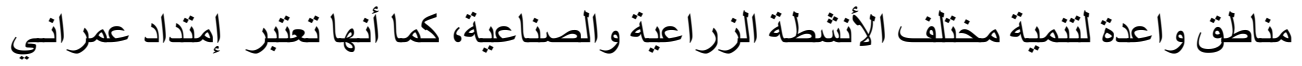
واسع لسكان الجمهورية.

يستمد البحث أهميته من أهمية إنتاج محاصيل الخضر لأهميتها الهاء الغذائية أهمية البحث:

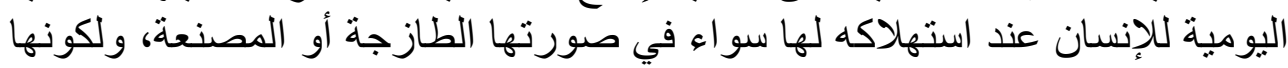

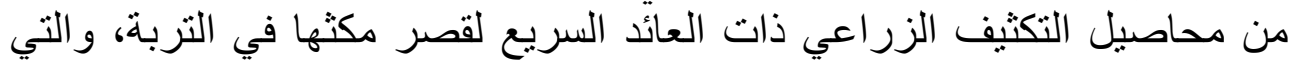

(1) وزارة التخطيط و الاستتمار،: خطة الدولة العاجلة للتنمية الشاملة ، قسم التنميــة القطاعية، ميزانية 
تستهدف تحقيق الأمن الغذائي القومي نظر ا للقيمة النقدية لتلك المحاصيل و التى تعد التحد

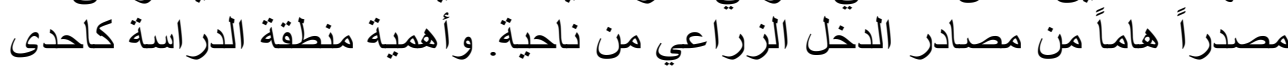

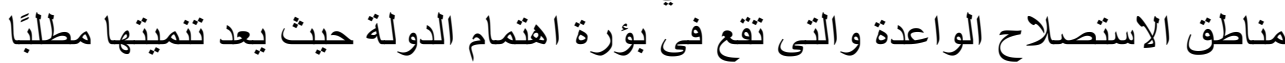

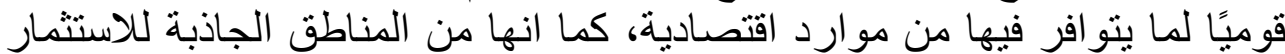

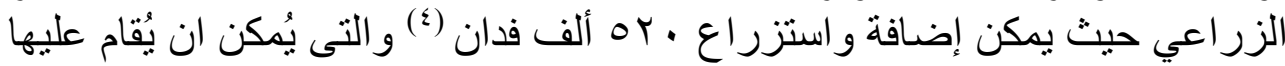

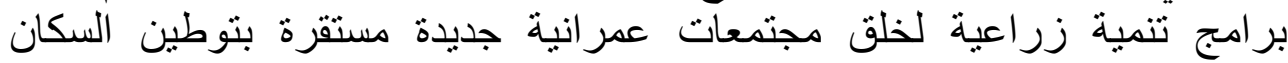

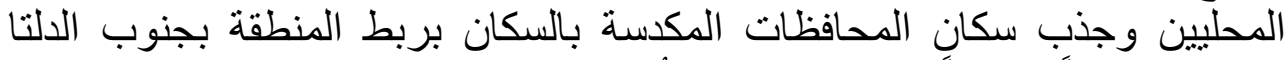

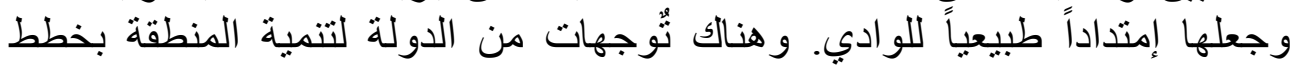

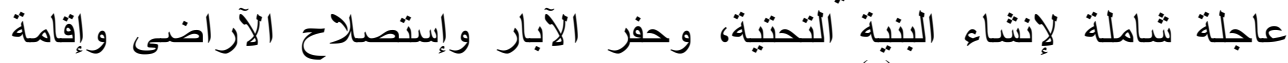

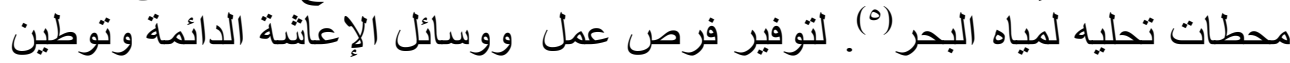

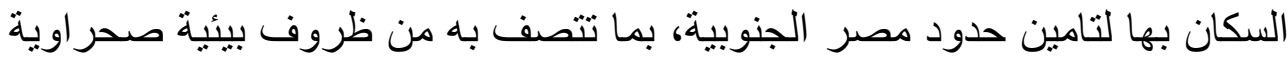

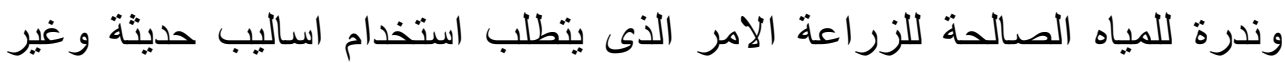

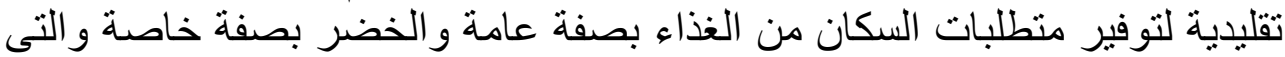

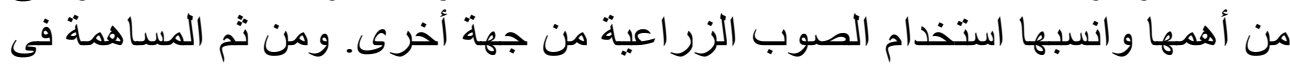

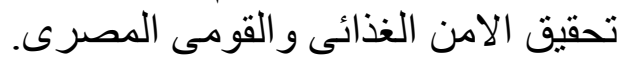

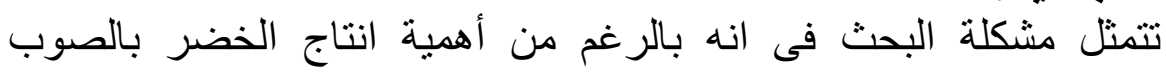

\section{المشكاة البحثية:} الزراعية بما توفرة من انتاج وفير للخضر يمكن ان يساهم فى تقليل الفجوة بين

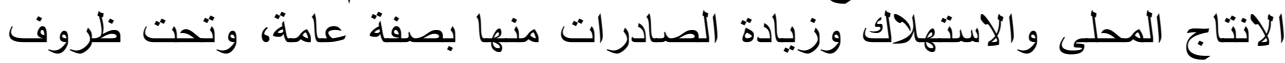

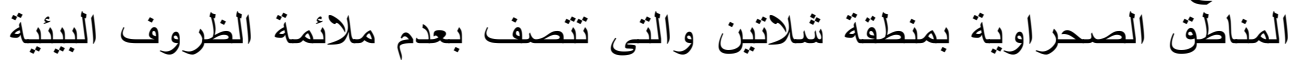

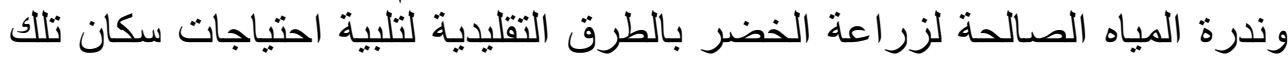

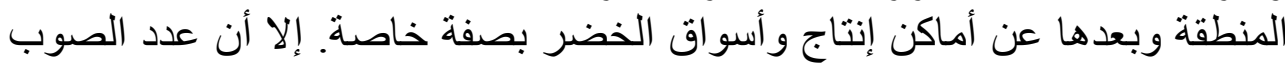

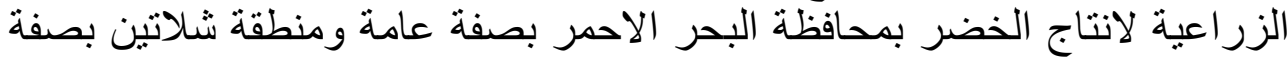

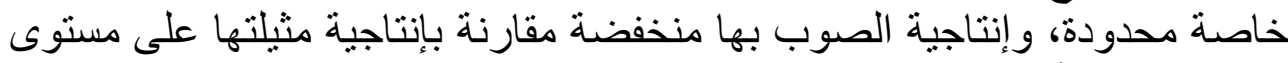

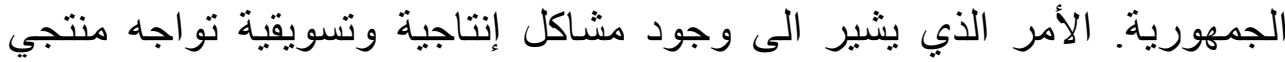

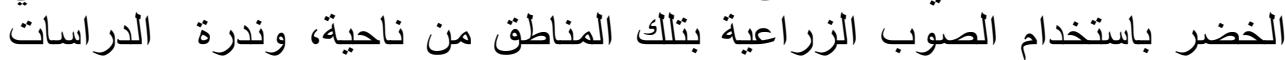

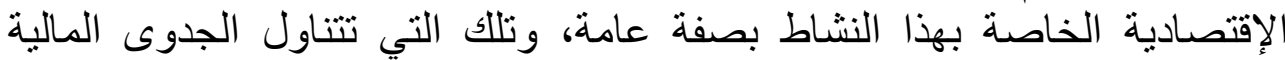
لإنتاج الخضر باستخدام تكنولوجيا الصوب الزراعية في المناطق الصحر اوية بصنة بصفة 
يهدف البحث بصفة أساسية الى دراسة اقتصاديات انتاج محصولى الخيار و الفلفل بالصوب الزراعية كأهم محصولين من محاصيل الخضر بادية بالنسبة لعدد

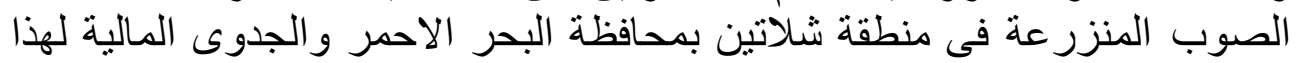

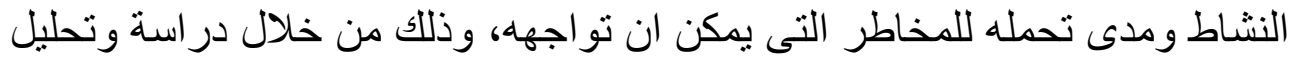

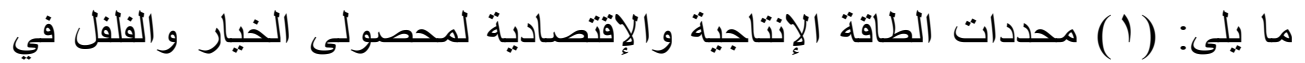

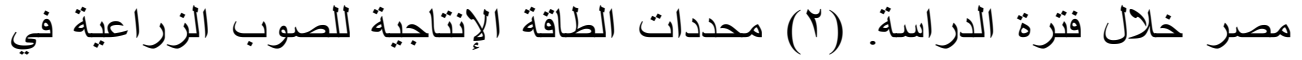

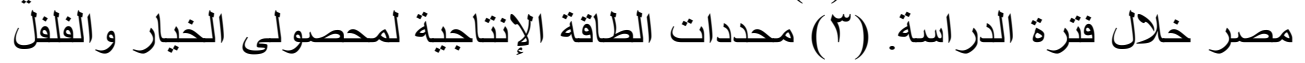

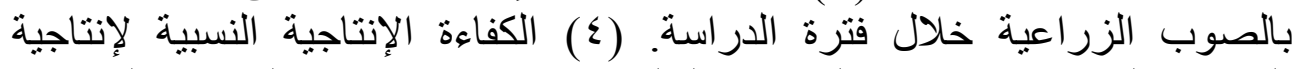

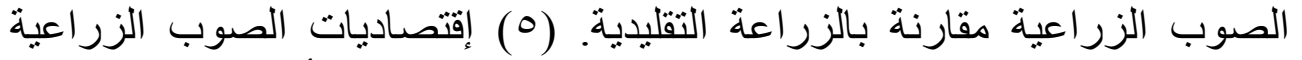
لمحصولى الخيار والفلفل بمنطقة شلاتين بمحافظة البحر الأحمر. (ب) (ب) التحليل

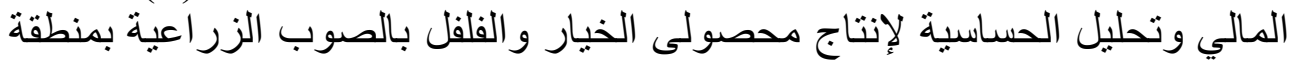

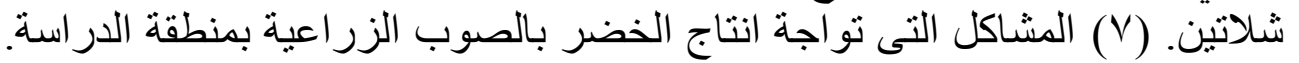

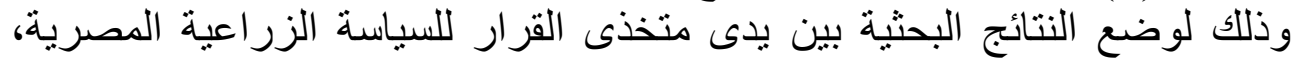

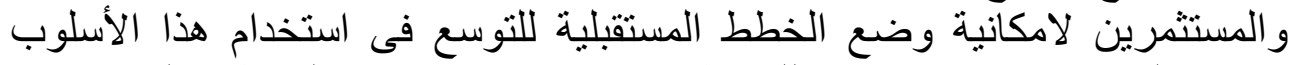

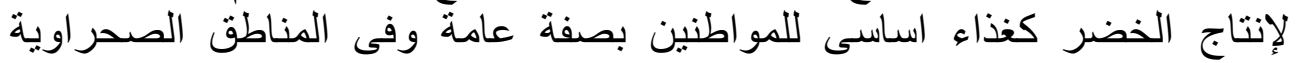
المستهدف تتميتها وتعمير ها باقامة مجتمعات سكنية مستقرة وتوطين السكان بها

\section{الإسلوب البحثي ومصادر البيانات:}

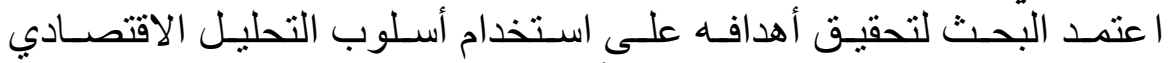

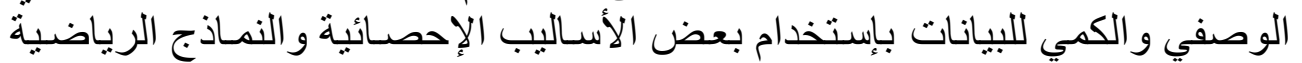

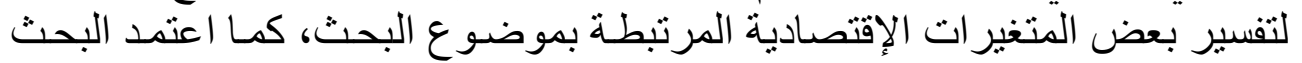

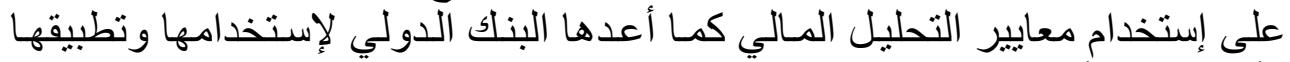

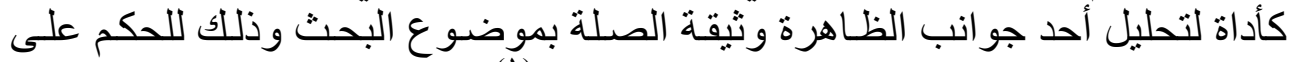

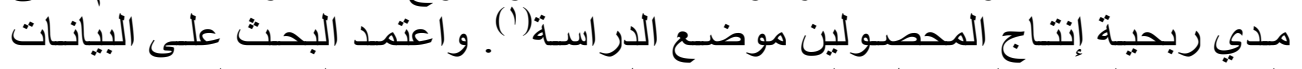

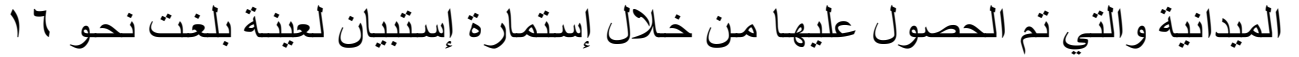

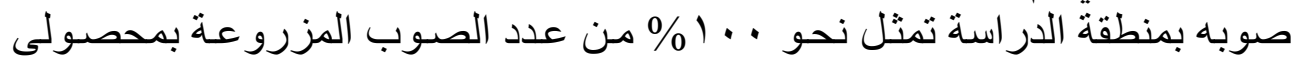

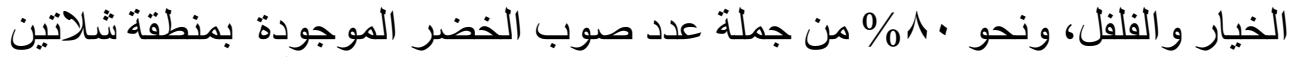

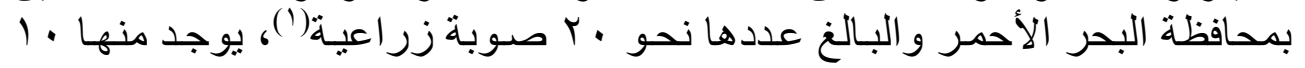

(1) حسن عبد الغفور العباسي (دكتور)، أخرون: تحليل إقتصادي للجدوي الإقتصادية لمشروع إنتاج وتصدير زهور

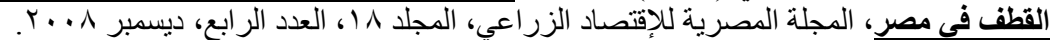

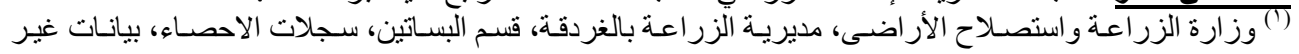




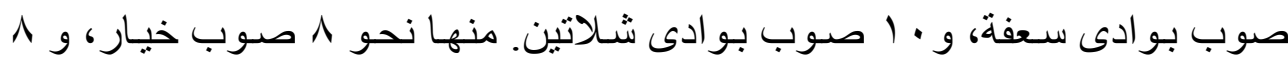

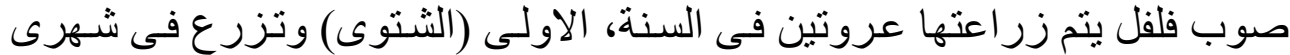

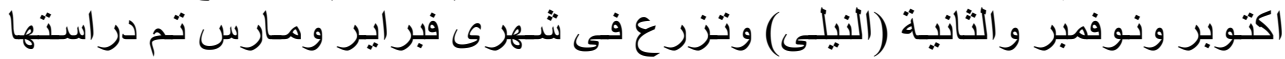

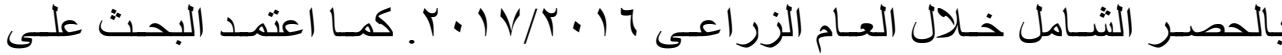

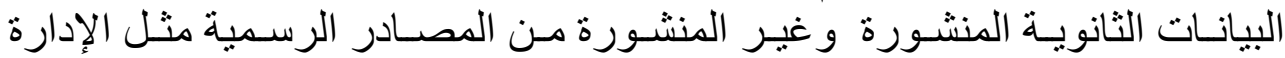

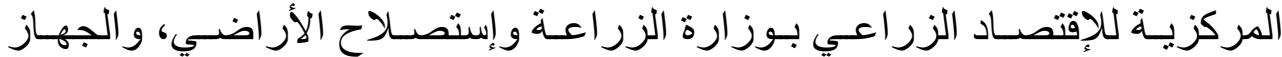

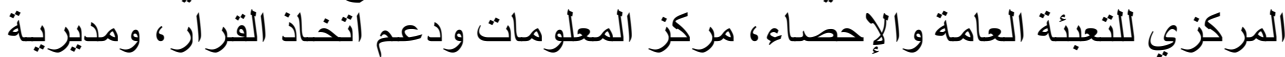

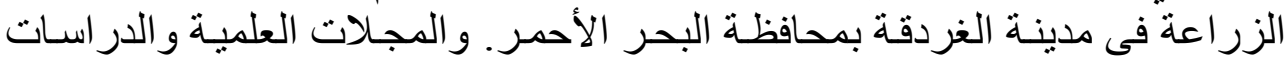

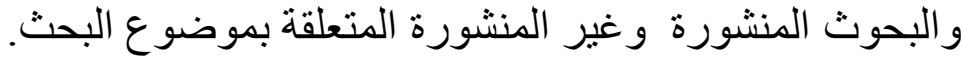

تقع منطقة شلاتين فى أقصى الركن الجنوبى الثرقى من الصـحر اء الثرقية

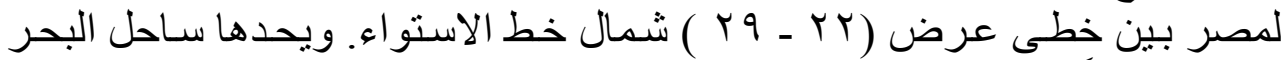

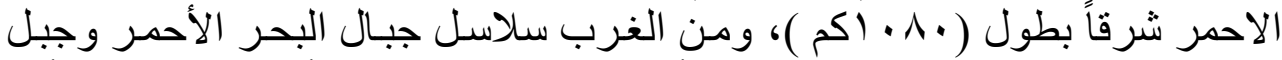

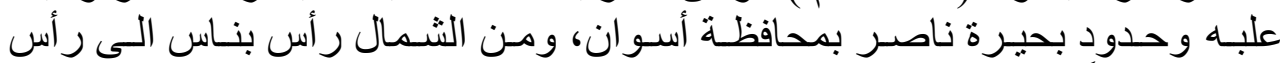

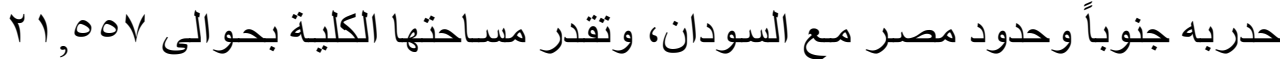

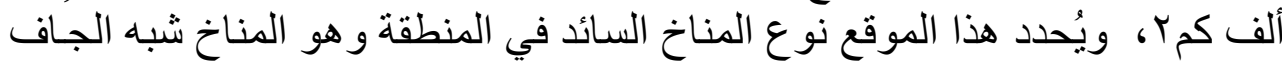

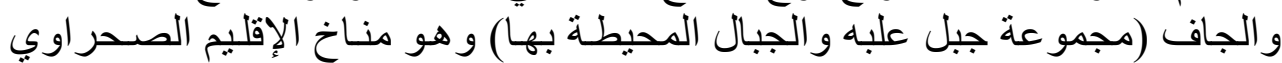

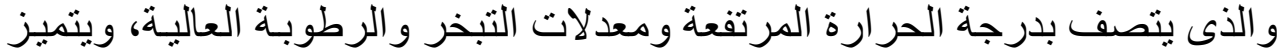

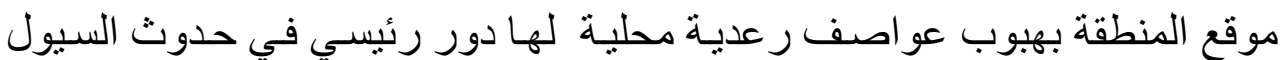
بالمنطقة، كما تتسم المنطقة بهبوب عو اصف رملية تَحدث عادة خلال فصلي الربيع

\section{النتائج البحثية ومناقشتها:}

أولاً: محددات الطاقة الإنتاجية والإقتصادية لمحصولى الدراسة:

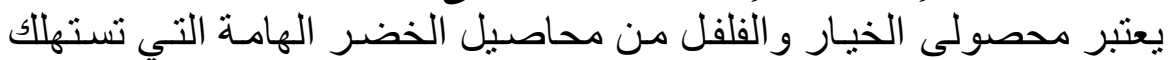

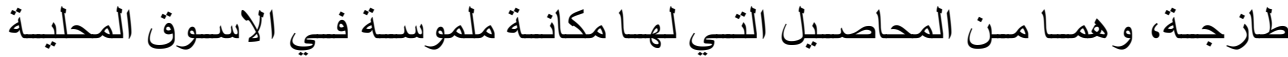

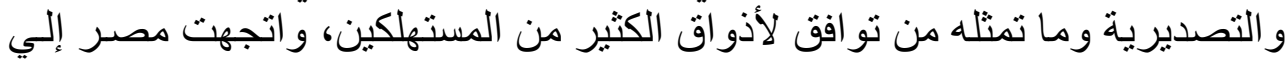
تنمية إنتاجهما بمعدلات كبيرة في السنو ات الأخيرة و انتشرت زئن زر اعتهمـا في منـاطق

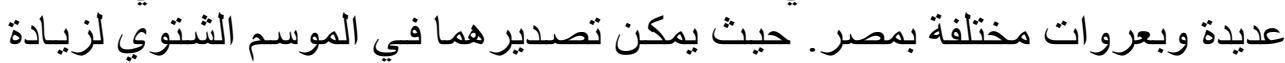

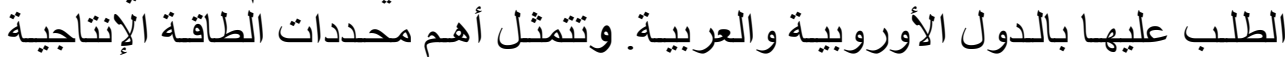




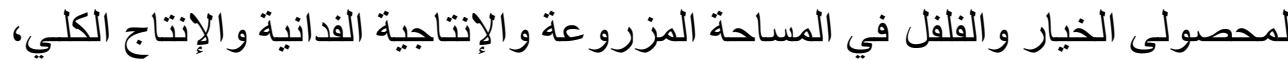

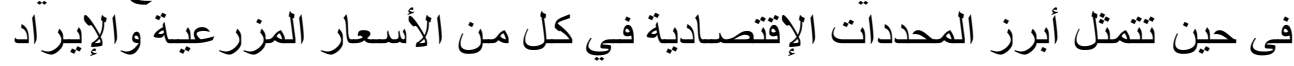

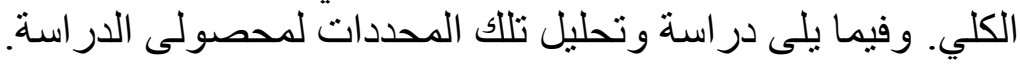

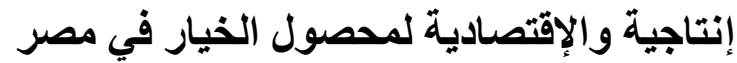

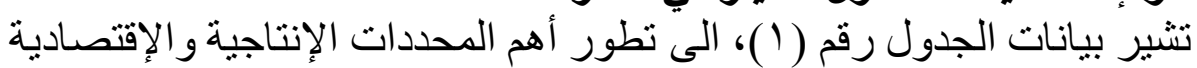

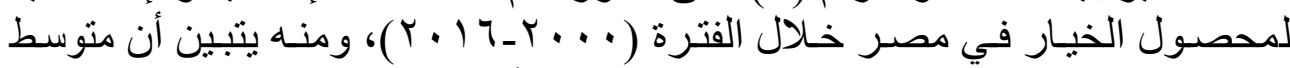

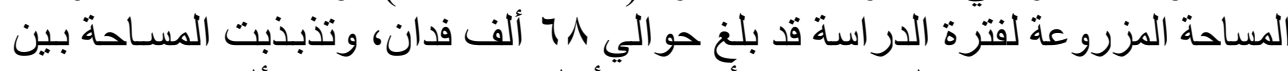

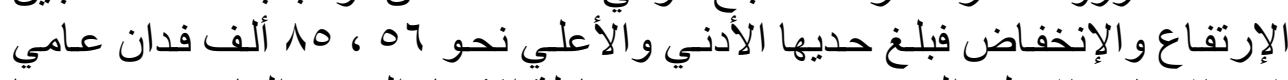

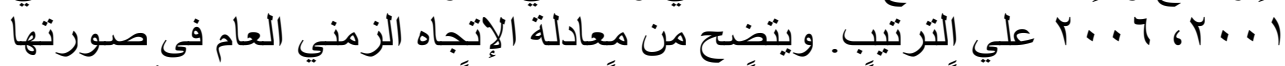

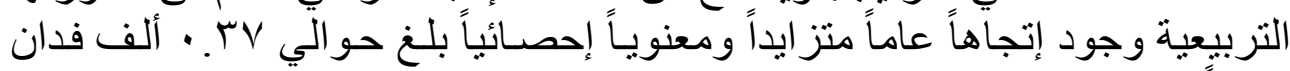

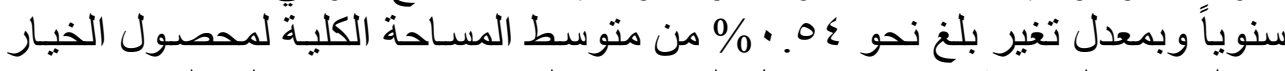

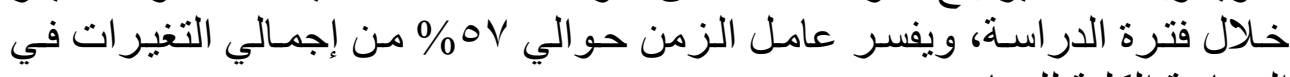

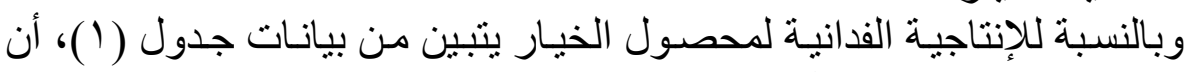

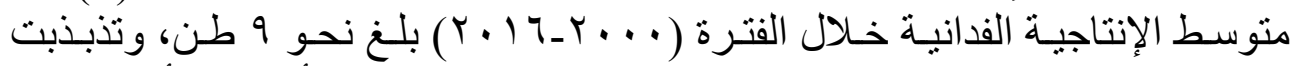

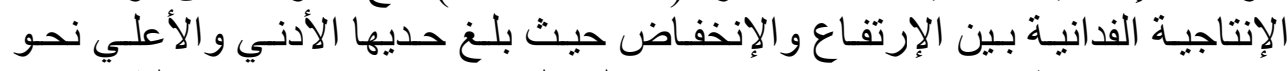
الز

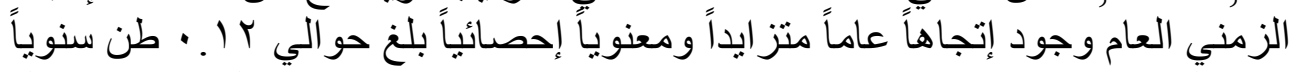

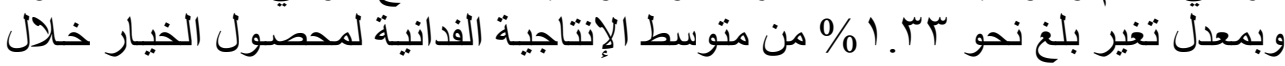

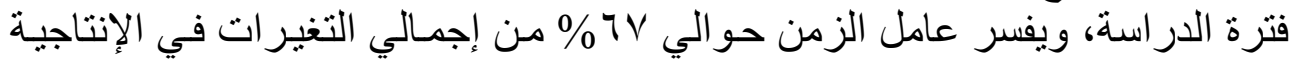

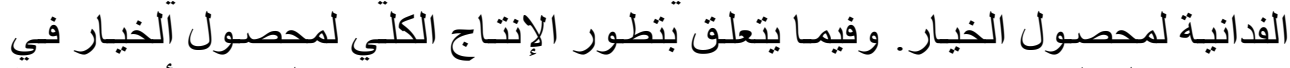

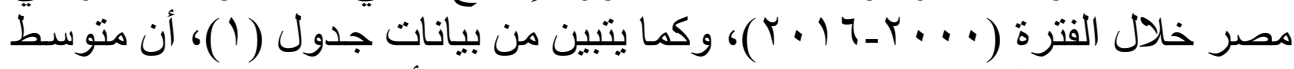

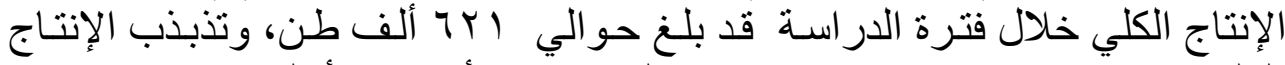

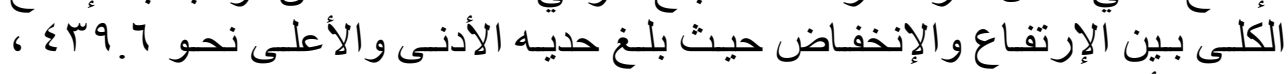

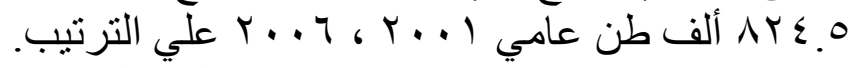

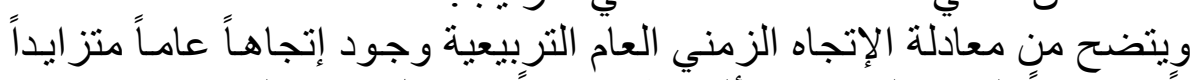

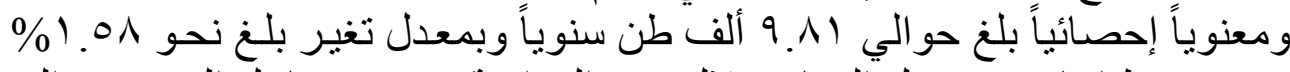

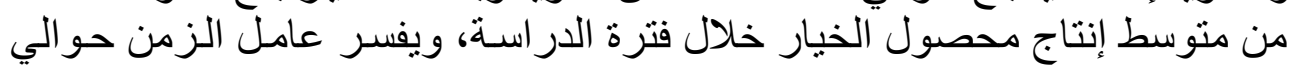

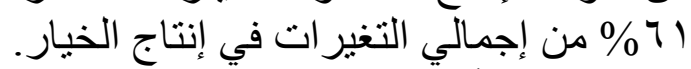

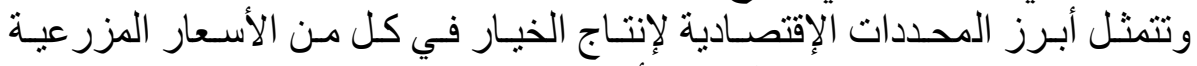

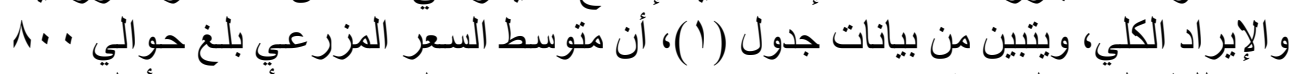

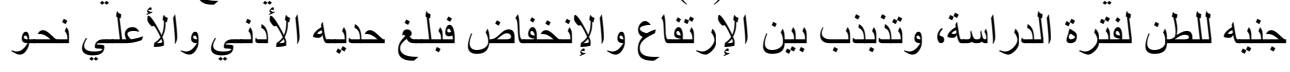




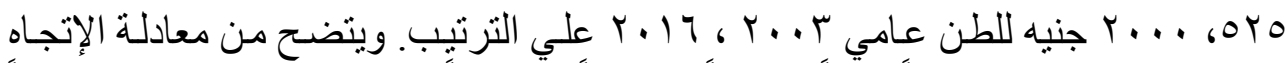

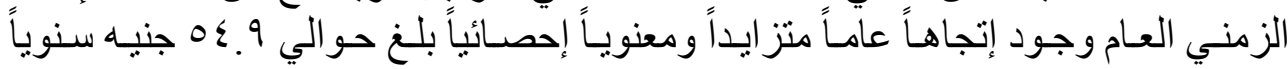

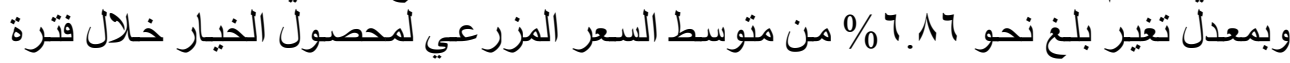

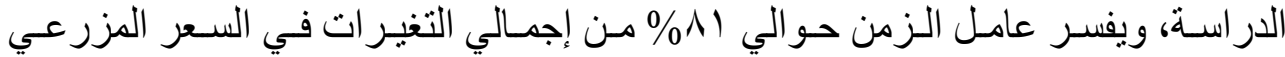
لمحصول الخيار.

جدول (1): معادلات الإتجاه الزمني العام لتطور أهم المحددات الإنتاجية

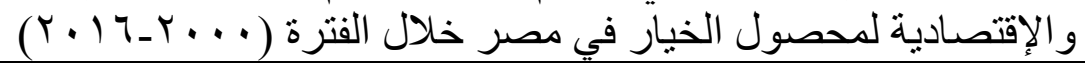

\begin{tabular}{|c|c|c|c|c|c|c|c|c|c|c|c|}
\hline $\begin{array}{l}\text { التغير } \\
\text { (\%) }\end{array}$ & التئير & معتامتلا & $F$ & $R^{2}$ & متوب & \multicolumn{2}{|c|}{ الحد الأدني } & \multicolumn{2}{|c|}{ الحد الأقصي } & الوحدة & البيان \\
\hline \multirow{2}{*}{$\begin{array}{l}\because 0 \leqslant \\
\varepsilon\end{array}$} & \multirow{2}{*}{${ }^{1)}{ }_{i}^{r V}$} & \multirow{2}{*}{$11 . \mathrm{rV}$} & \multirow{2}{*}{ *ะ. $\vee q$} & \multirow{2}{*}{$\ddot{v}$} & \multirow{2}{*}{71} & 04 & للمساحة & 10 & للمساحة & \multirow{2}{*}{ فذان) } & \multirow{2}{*}{ المزروء } \\
\hline & & & & & & $r \ldots r$ & السنة & r.. & السنة & & \\
\hline \multirow{2}{*}{${ }^{1 . r T}$} & \multirow{2}{*}{$\because .1 Y$} & \multirow{2}{*}{0.10} & \multirow{2}{*}{${ }^{*} r 1_{*} .0 \varepsilon$} & \multirow{2}{*}{$\ddot{v}^{\top}$} & \multirow{2}{*}{9} & Y.Ao & للانتاج & 9. . & للانتاج & \multirow{2}{*}{ (طن) } & \multirow{2}{*}{ الفدانية } \\
\hline & & & & & & $r \ldots$ & السنة & r.1. & السنة & & \\
\hline \multirow{2}{*}{1.01} & \multirow{2}{*}{ 1) 9.11} & \multirow{2}{*}{$1 \leqslant .70$} & \multirow{2}{*}{ *q.r } & \multirow{2}{*}{$i^{\top}$} & \multirow{2}{*}{ ITI } & $\begin{array}{c}\varepsilon r q . \\
T\end{array}$ & للانتاج & $A r \leqslant .0$ & للانتاج & \multirow{2}{*}{ (ألف طن) } & \multirow{2}{*}{ الإلتنيج } \\
\hline & & & & & & $r \ldots l$ & السنة & r... & السنة & & \\
\hline \multirow{2}{*}{$\begin{array}{c}7.10 \\
9\end{array}$} & \multirow{2}{*}{$0 \leqslant .9$} & \multirow{2}{*}{ rI.Vr } & \multirow{2}{*}{ * $\leqslant$ * } & \multirow{2}{*}{$i^{\wedge}$} & \multirow{2}{*}{ A.. } & oro & للقيمة & r... & للقيمة & \multirow{2}{*}{ (جنيه/طن } & \multirow{2}{*}{ المزر عية } \\
\hline & & & & & & $r \ldots r$ & السنة & r.17 & السنة & & \\
\hline \multirow{2}{*}{ ^. . } & \multirow{2}{*}{ זיד. } & \multirow{2}{*}{ ro. $1 \varepsilon$} & \multirow{2}{*}{$\left.{ }^{*} v_{*}, y\right)$} & $\cdot . \wedge$ & $\forall Y$ & ๕. 1 & للقيمة & ${ }_{0}^{10} \cdot r$ & للقيمة & (ألف & الإير اد \\
\hline & & & & $\lambda$ & & $r \ldots r$ & السنة & $r .17$ & السنة & ( & \\
\hline
\end{tabular}

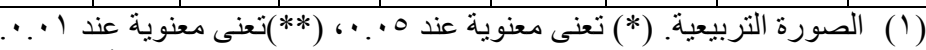

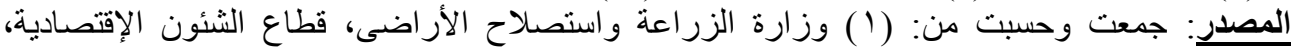

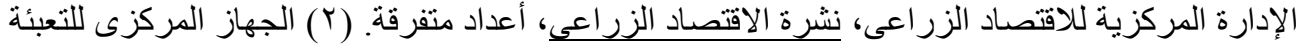
العامة والإحصاء، الكتاب الإحصائي السنوى، ألعداء الإداد متفرقة.

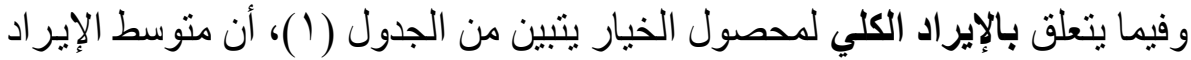

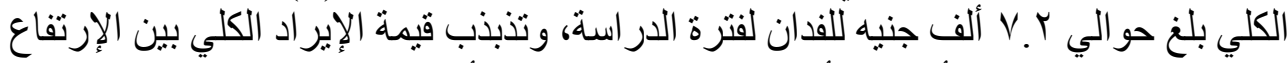

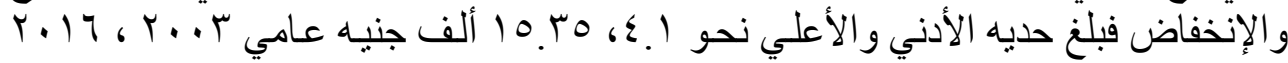
ويتضح من معادلة الإتجاه الزمني العام وجود إتجاهـاً عامـاً متز ايداً و معنوياً إحصـائياً علي الترتيب.

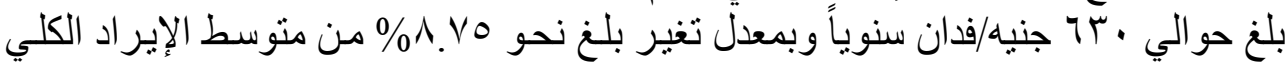

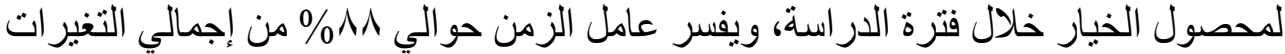
في الإير اد الكلي لمحصول الخيار. 


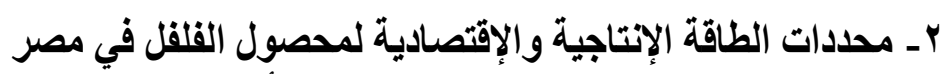

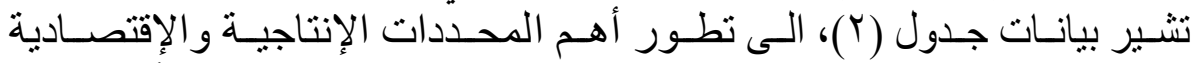

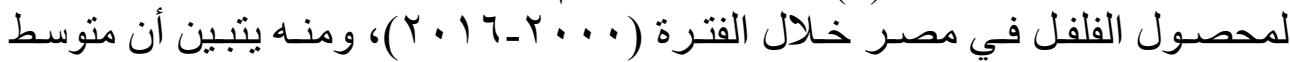

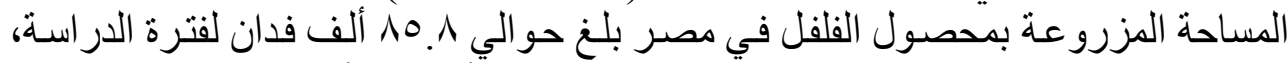

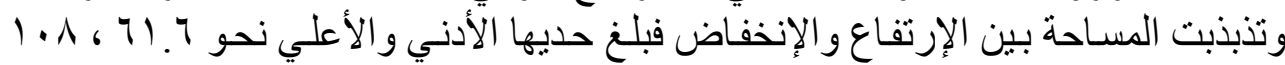

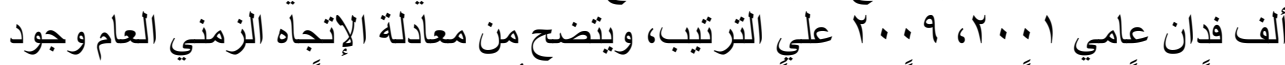

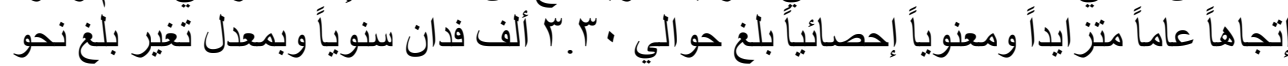

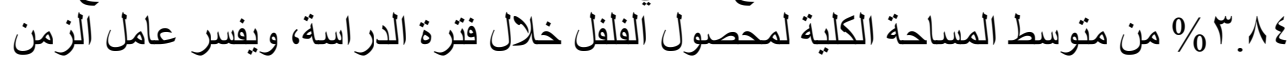

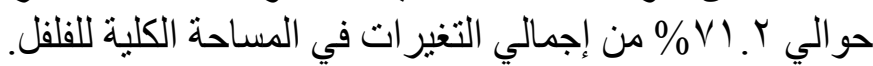

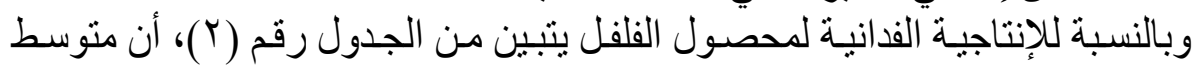

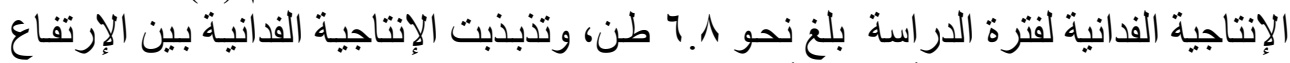

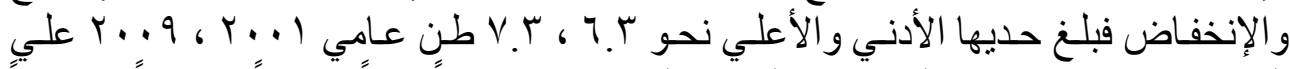

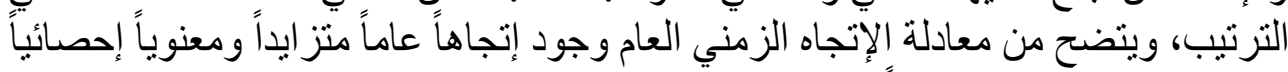

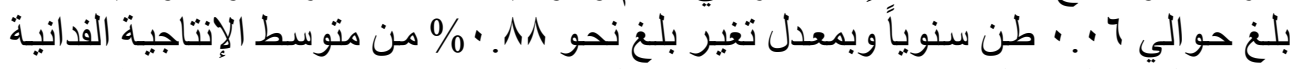

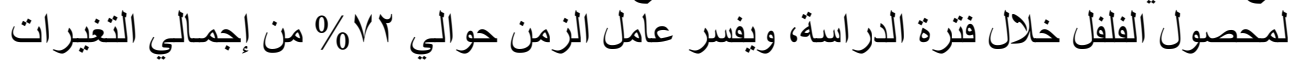

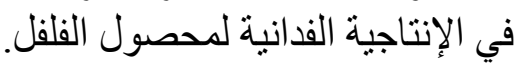

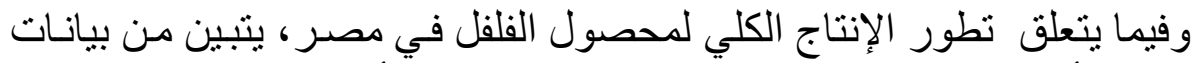

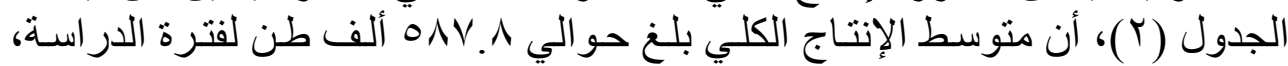

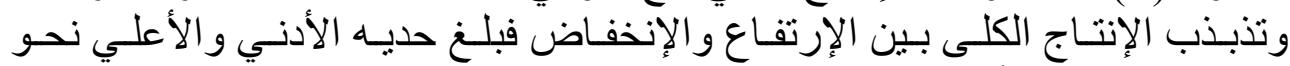

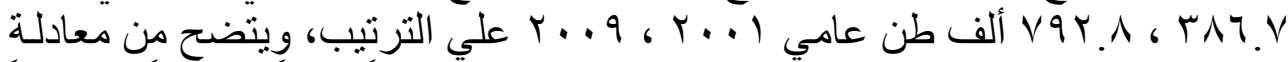

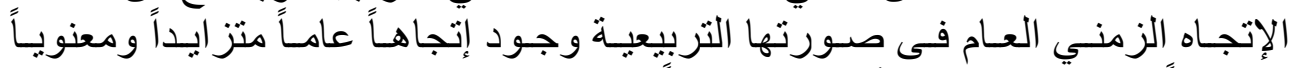

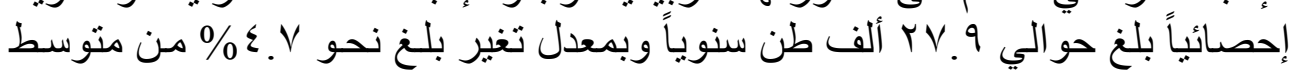

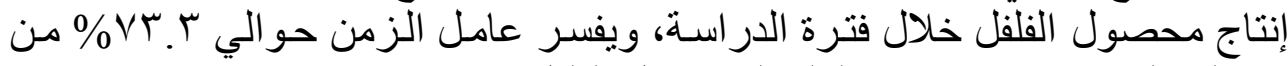

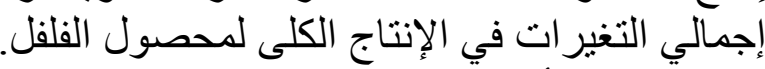

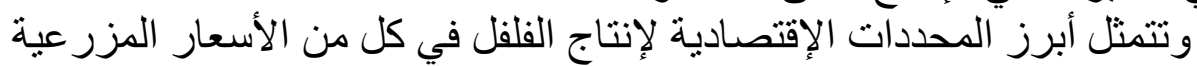

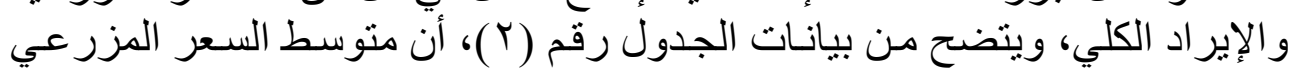

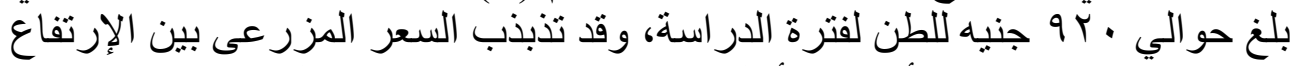

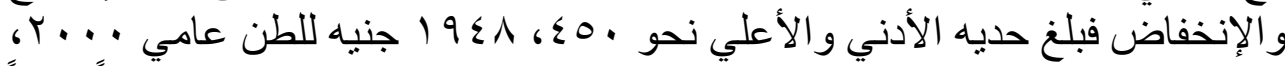

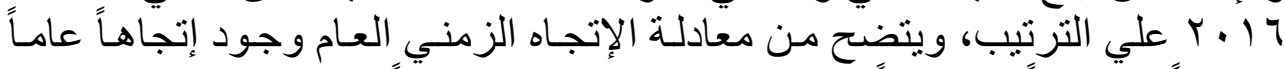

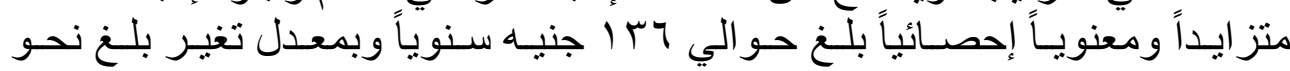

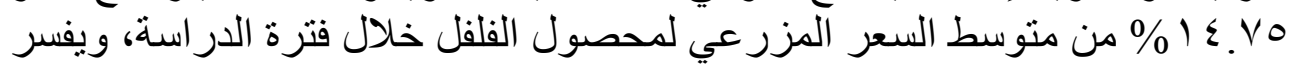

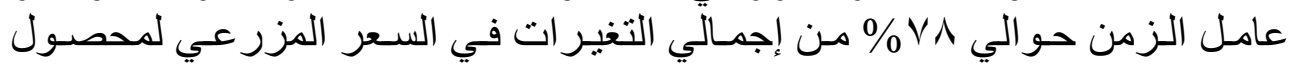


جدول (Y): معادلات الإتجاه الزمني العام لتطور أهم المحددات الإنتاجية

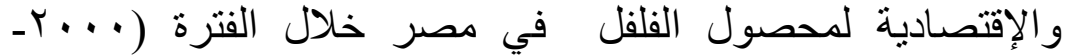

$(Y \cdot) \top$

\begin{tabular}{|c|c|c|c|c|c|c|c|c|c|c|c|}
\hline $\begin{array}{l}\text { التنغير } \\
\text { (\%) }\end{array}$ & التنغير & |الإختلاف & $F$ & $R^{2}$ & متتوسط & \multicolumn{2}{|c|}{ الحد الأدني } & \multicolumn{2}{|c|}{ الحد الأقصي } & الة & البيان \\
\hline \multirow{2}{*}{ 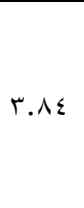 } & \multirow{2}{*}{ r.r. } & \multirow{2}{*}{$\begin{array}{c}\text { IV.V } \\
\text { V }\end{array}$} & \multirow{2}{*}{$\begin{array}{l}\text { YV.1T } \\
\text { *** }\end{array}$} & \multirow{2}{*}{$\begin{array}{c}. \cdot r \\
r\end{array}$} & \multirow{2}{*}{$\begin{array}{c}10 . V \\
V\end{array}$} & $\begin{array}{l}71.0 \\
V\end{array}$ & للمساح & $\begin{array}{l}1 . \lambda . \\
. r\end{array}$ & لل & \multirow{2}{*}{ فدان) } & \multirow{2}{*}{ المزاد : } \\
\hline & & & & & & $r \ldots l$ & السنة & $r \ldots q$ & السنة & & \\
\hline \multirow[b]{2}{*}{.$\wedge 1$} & \multirow[b]{2}{*}{$\ldots 4$} & \multirow[b]{2}{*}{ צ. } & \multirow{2}{*}{$\begin{array}{l}\text { YY.VY } \\
* * *\end{array}$} & \multirow{2}{*}{$\begin{array}{c}\cdot . v 1 \\
y\end{array}$} & \multirow[b]{2}{*}{ T.A. } & T.YA & للانتاجية & $V . T \varepsilon$ & للانتاجية & \multirow[b]{2}{*}{ (طن) } & \multirow{2}{*}{ الفدانة الإنتاج } \\
\hline & & & & & & r... & السنة & r...q & السنة & & \\
\hline \multirow[t]{2}{*}{$\varepsilon . \vee \varepsilon$} & \multirow{2}{*}{$\begin{array}{c}Y Y . \wedge Y \\
\text { (') }\end{array}$} & \multirow{2}{*}{$\begin{array}{c}r .0 \\
\wedge\end{array}$} & \multirow{2}{*}{ 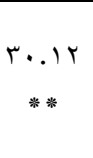 } & \multirow{2}{*}{$\begin{array}{c}. \cdot v r \\
r\end{array}$} & \multirow{2}{*}{$\begin{array}{l}\text { ONV. } \\
\text { NI }\end{array}$} & $\begin{array}{c}\text { rAT. } \\
79\end{array}$ & للانتاج & $\begin{array}{c}\text { Var. } \\
\wedge \varepsilon\end{array}$ & للانتاج & \multirow{2}{*}{ (ألف) } & \multirow{2}{*}{ الكلي } \\
\hline & & & & & & $r . .$. & السنة & $r \ldots q$ & السنة & & \\
\hline \multirow{2}{*}{$\begin{array}{c}1 \varepsilon . V \\
0\end{array}$} & \multirow{2}{*}{$\begin{array}{c}150.0 \\
\wedge\end{array}$} & \multirow{2}{*}{$70 .}$. & \multirow{2}{*}{ 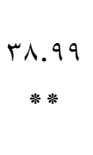 } & \multirow{2}{*}{$\begin{array}{c}. \cdot v \wedge \\
1\end{array}$} & \multirow[b]{2}{*}{ QY. } & so. & للقيمة & 19 19 & للقيمة & \multirow{2}{*}{ (طن) } & \multirow{2}{*}{ المزرء } \\
\hline & & & & & & $\uparrow \ldots$ & السنة & $r .14$ & السنة & & \\
\hline \multirow{2}{*}{$\begin{array}{c}10 . r \\
\wedge\end{array}$} & \multirow[t]{2}{*}{. .91} & \multirow{2}{*}{$\begin{array}{c}T V . V \\
q\end{array}$} & \multirow{2}{*}{$\begin{array}{l}\varepsilon 1 . \text { ro }^{\prime} \\
* * *\end{array}$} &. .11 & $7 . r V$ & r.9. & للقيمة & $\begin{array}{c}15.0 \\
7\end{array}$ & للقيمة & (ألف & الإيراد \\
\hline & & & & & & $r \ldots$ & السنة & $r .11$ & السنة & فدان) & \\
\hline
\end{tabular}

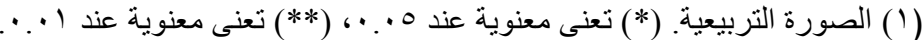

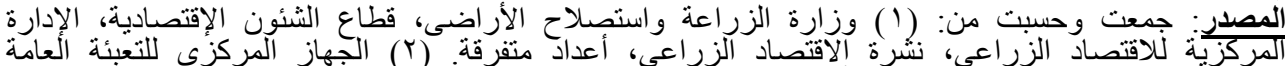

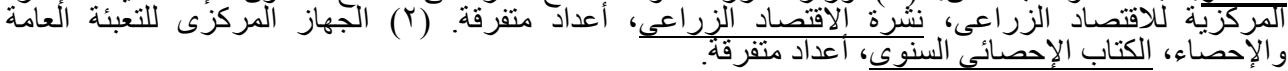

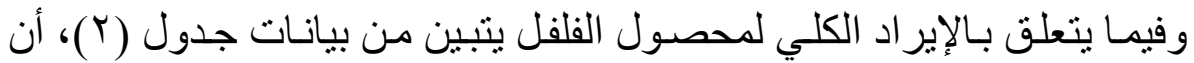

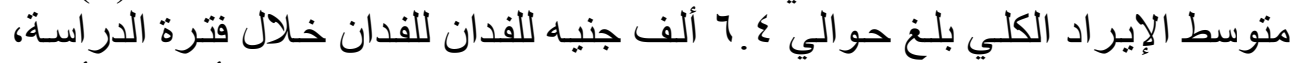

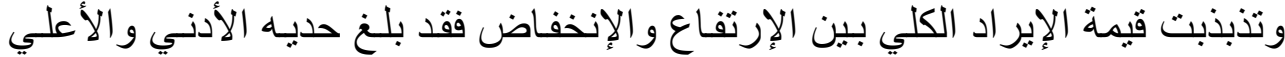

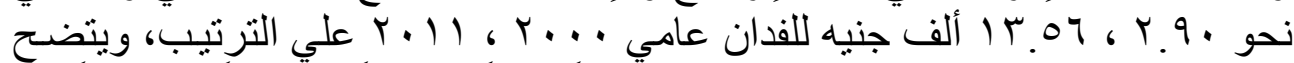

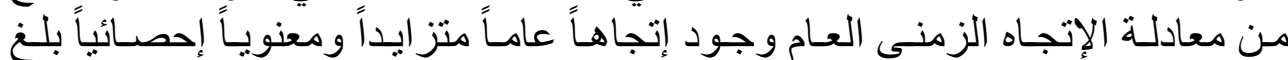

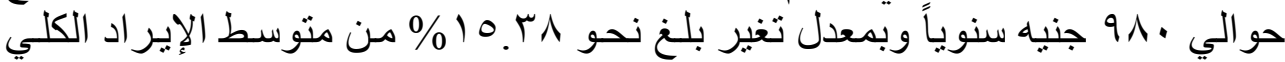

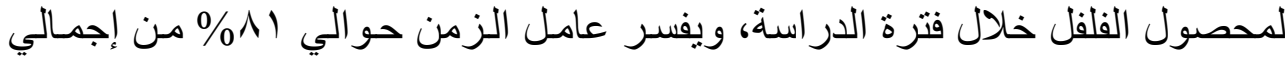
التغير ات في الإير اد الكلي لمحصول فلفول الفلفل. 


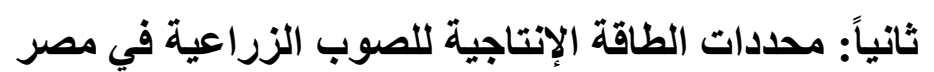

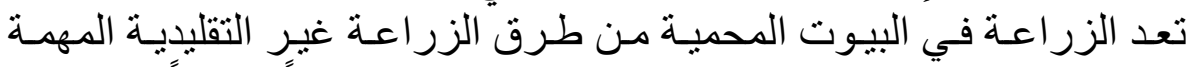

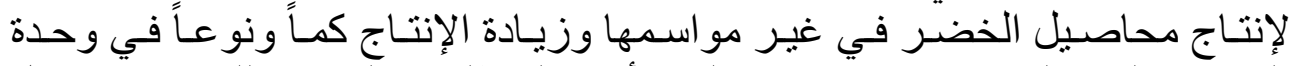

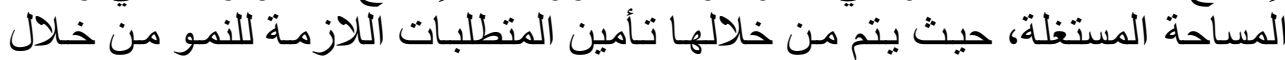

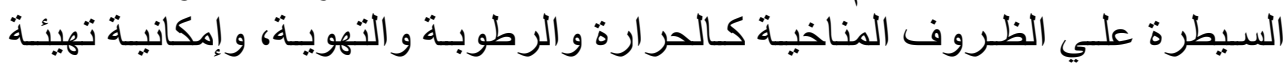

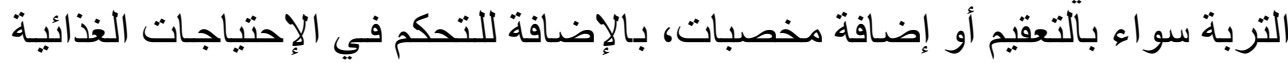

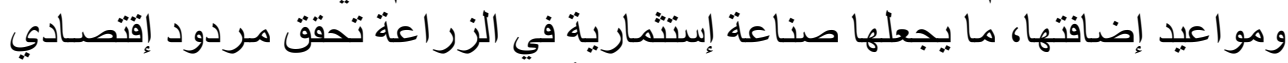

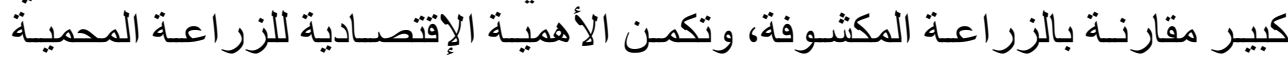

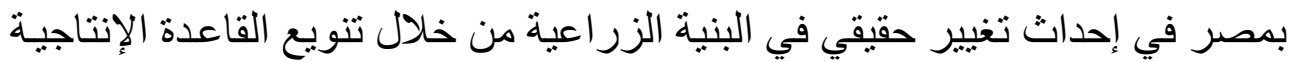

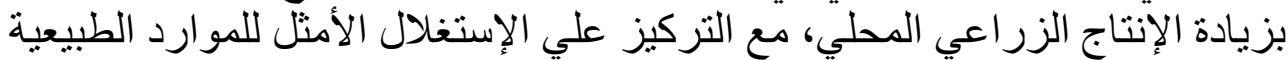

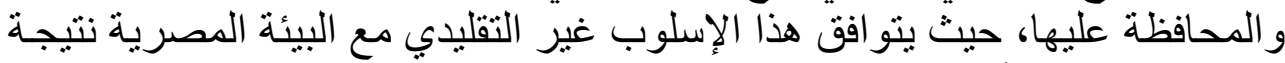
لإنخفاض جودة الأر اضي و الفقر المائي الحالي و المستقبلي.

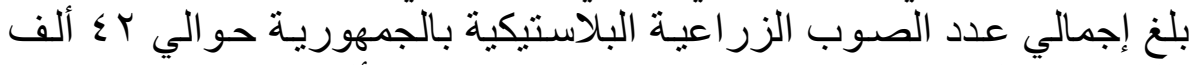

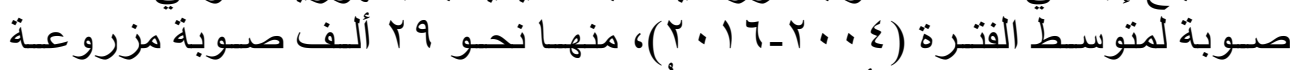

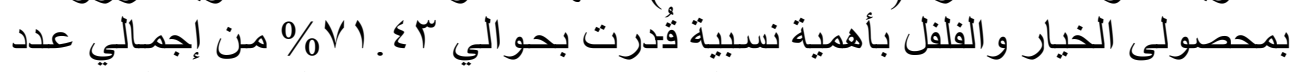

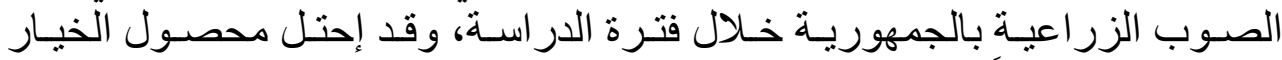

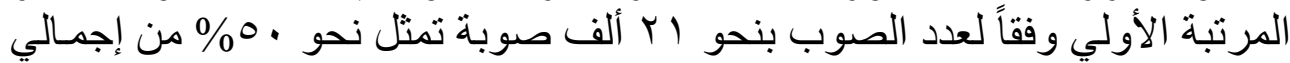

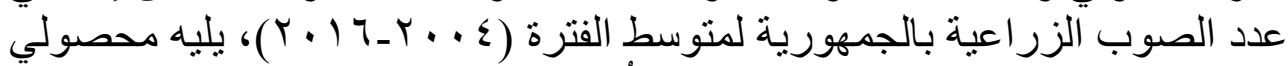

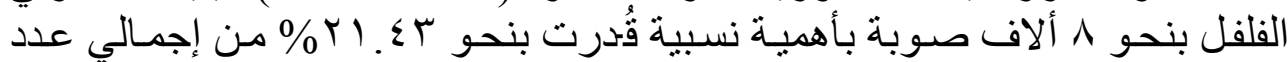

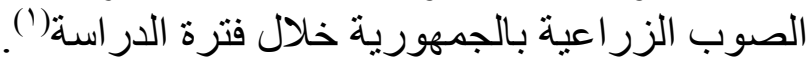

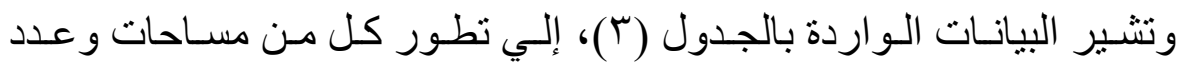

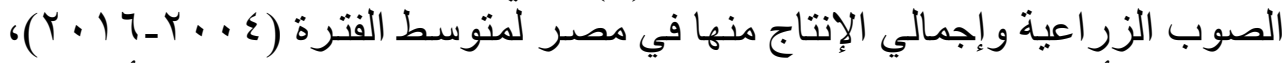

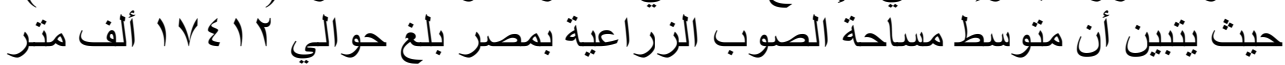

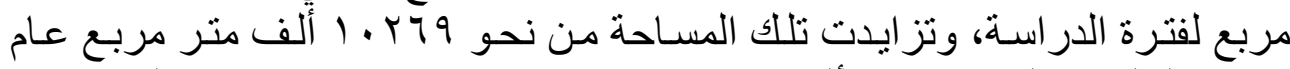

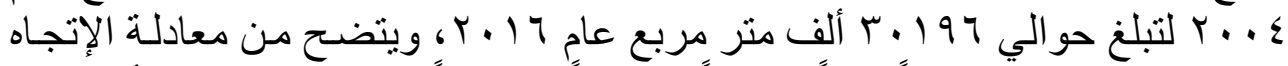

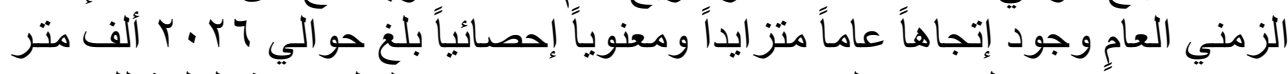

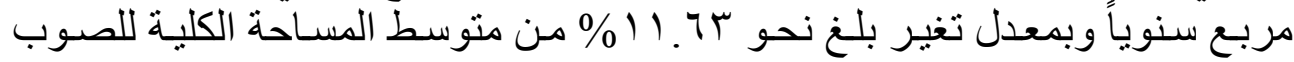

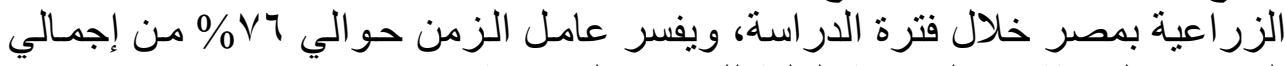
التغير ات الحادثة في المساحة الكلية للصوب فئرة الزبة ولفير عاعلة الزية 


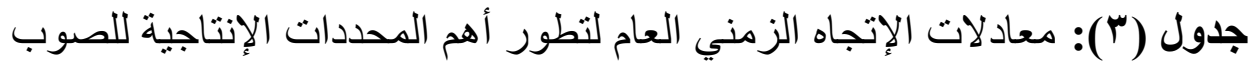

\begin{tabular}{|c|c|c|c|c|c|c|c|c|c|c|c|}
\hline التغيرل & التنغير & ألفتلا & $F$ & $R^{2}$ & متقرة & \multicolumn{2}{|c|}{ الحد الأدني } & \multicolumn{2}{|c|}{ الحد الأقصي } & 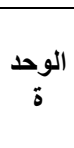 & البيان \\
\hline \multirow{2}{*}{${ }_{r}^{11}{ }^{\top}$} & \multirow{2}{*}{ Th. } & \multirow{2}{*}{$\begin{array}{c}r .0 \\
\varepsilon\end{array}$} & \multirow{2}{*}{$\begin{array}{r}r . Y \cdot \\
* *\end{array}$} & \multirow{2}{*}{$\cdot{ }_{r}^{V T}$} & \multirow{2}{*}{$\begin{array}{c}1 V \varepsilon\} \\
Y\end{array}$} & $\begin{array}{c}1.17 \\
9\end{array}$ & لالمة & $\begin{array}{c}r .19 \\
7\end{array}$ & لالمة & \multirow{2}{*}{$\begin{array}{l}\text { (ألف } \\
\text { (T) }\end{array}$} & \multirow{2}{*}{ حة المسا } \\
\hline & & & & & & r... & السنة & r.17 & السنة & & \\
\hline \multirow[t]{2}{*}{9.7} & \multirow[t]{2}{*}{ ") } & \multirow{2}{*}{$\stackrel{\varepsilon}{r} \cdot$} & \multirow{2}{*}{$\begin{array}{c}r r . y \\
* *\end{array}$} & \multirow{2}{*}{$\cdot{ }_{1}^{\text {ArA }}$} & \multirow[t]{2}{*}{$r$} & $\begin{array}{c}r \leqslant . Y \\
Y\end{array}$ & للصة & $71 . \mathrm{ro}^{\circ}$ & للصة & \multirow{2}{*}{ صبة } & \multirow{2}{*}{ الصو } \\
\hline & & & & & & $r \ldots \varepsilon$ & السنة & $r .17$ & السنة & & \\
\hline \multirow{2}{*}{$9 . \cdot r$} & \multirow{2}{*}{1910.9} & \multirow{2}{*}{$r \cdot{ }^{r}$} & \multirow{2}{*}{$\begin{array}{c}1 r . \wedge r \\
* *\end{array}$} & \multirow{2}{*}{$\overbrace{9}^{.74 \pi}$} & \multirow{2}{*}{$\begin{array}{c}1 \times 4 . r \\
\varepsilon\end{array}$} & 97. & للكمية & rYI.T & للكمية & \multirow{2}{*}{ (أن) } & \multirow{2}{*}{ الإنتاج } \\
\hline & & & & & & $r \ldots \varepsilon$ & السنة & 5.17 & السنة & & \\
\hline
\end{tabular}

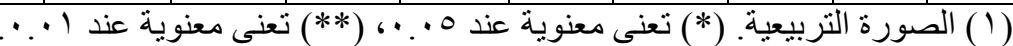

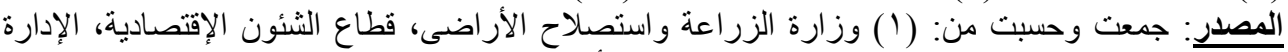

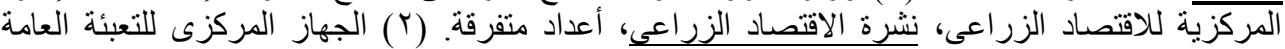
و الإحصاء، الكتاب الإحصائى السنوي، أعداد متفرقة.

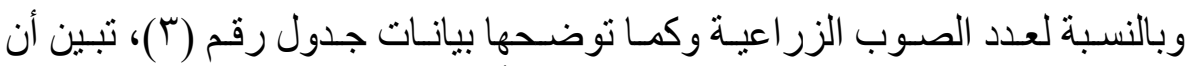

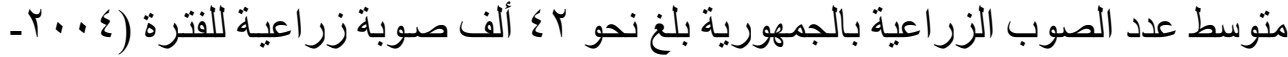

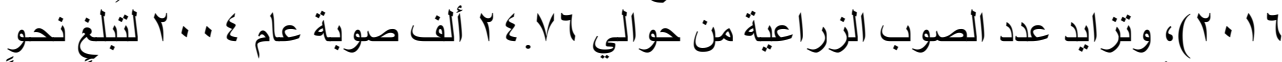

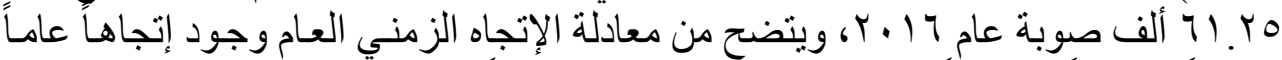

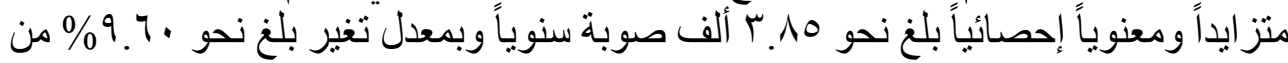

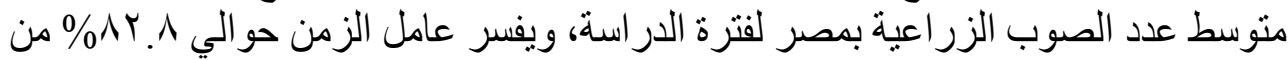
إجمالي عدد الصوب الزراعية.

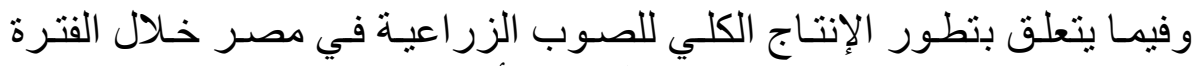

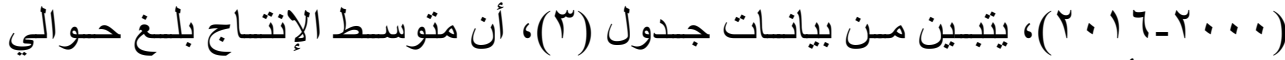

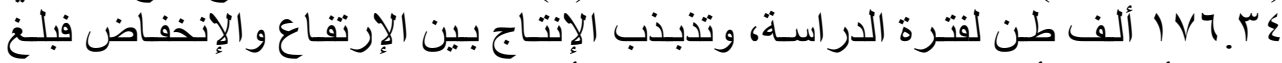

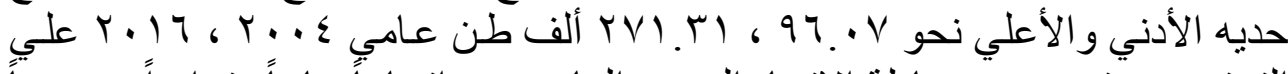

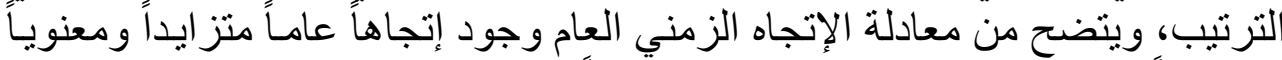

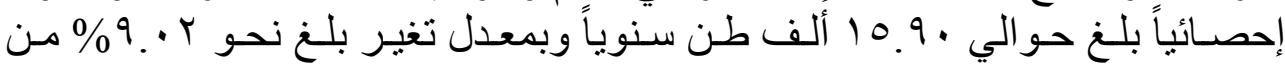

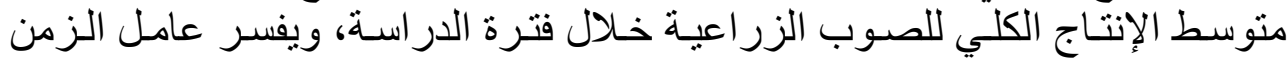

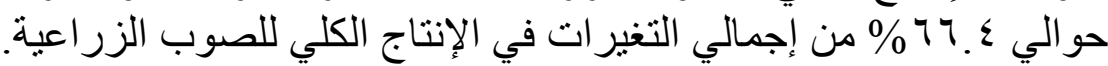

ثالثاً: محددات الطاقة الإتتاجية لمحصولى الخيار والقلقل بالصوب الزراعية فى مصر.

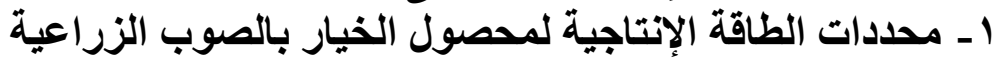

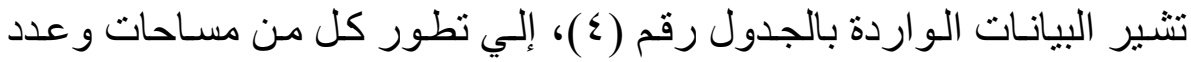

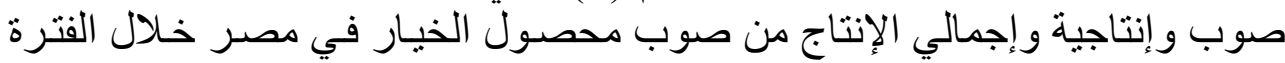




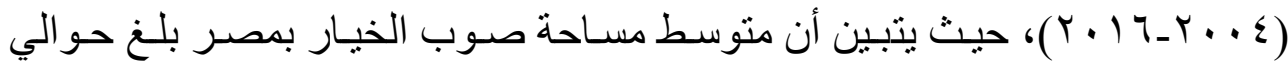

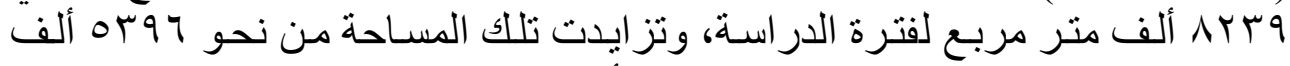

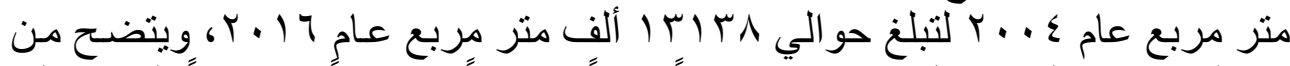

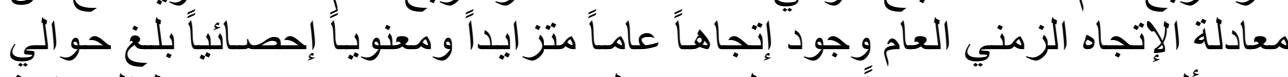

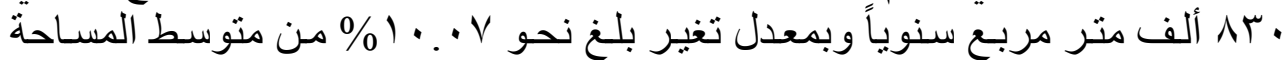

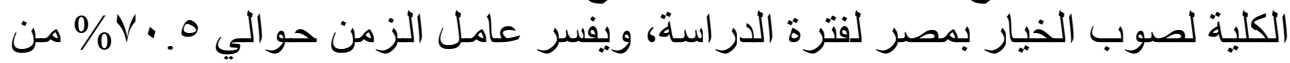

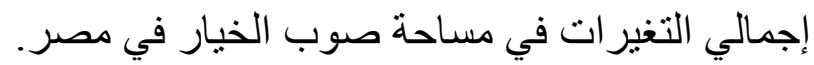

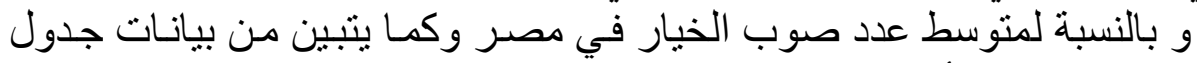

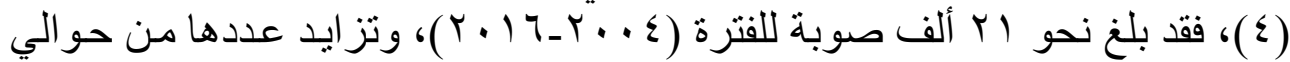

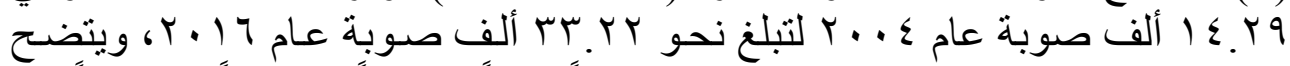

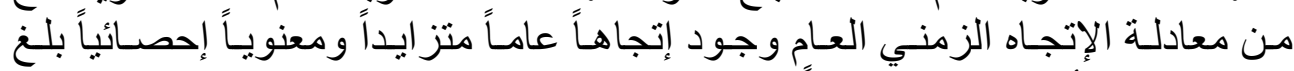

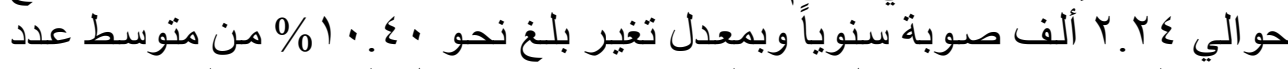

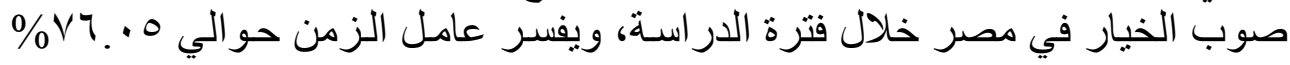
من إجمالي عدد صوب في الخيار في مصر فرة الار

جدول (๕): معادلات الإتجاه الزمني العام المعالم لتطور أهم المحددات الإنتاجية

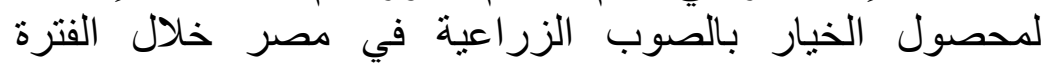

$\left(Y \cdot 1 \tau_{-}, r \cdot \varepsilon\right)$

\begin{tabular}{|c|c|c|c|c|c|c|c|c|c|c|c|}
\hline التغير & السنغير & 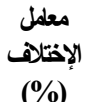 & $F$ & $R^{2}$ & القترة & \multicolumn{2}{|c|}{ الحد الأنني } & \multicolumn{2}{|c|}{ الد الأقصّي } & الوحة & الييان \\
\hline \multirow{2}{*}{$1 \because \cdot v$} & \multirow{2}{*}{ הr. } & \multirow{2}{*}{ r..10 } & \multirow{2}{*}{$* * 17, Y \varepsilon$} & \multirow{2}{*}{$\cdot v .01$} & \multirow{2}{*}{ Arrq } & or 97 & اللمسلحة & גזוTו & اللمسلحة & \multirow{2}{*}{ (ألف ب) } & \multirow{2}{*}{ المسلحة } \\
\hline & & & & & & Y... & السنة & $r .17$ & السنة & & \\
\hline \multirow{2}{*}{$1 \cdot . \varepsilon$} & \multirow{2}{*}{ T.Y } & \multirow{2}{*}{ Tז.Tr } & \multirow{2}{*}{ **YY,YY } & \multirow{2}{*}{.97 .0} & \multirow{2}{*}{ r) } & $1 \leqslant .99$ & اللصوبة & TT.K & اللصوبة & \multirow{2}{*}{ صوبة } & \multirow{2}{*}{ الصوب } \\
\hline & & & & & & r... & السنة & $r .17$ & السنة & & \\
\hline \multirow{2}{*}{1.00} & \multirow{2}{*}{ ('). .19 - } & \multirow{2}{*}{15.70} & \multirow{2}{*}{ ש } & \multirow{2}{*}{. vror } & \multirow{2}{*}{ IT.KT } & $9 . \wedge \Sigma$ & للانتاجية & $1 \leq .94$ & للانتاجية & \multirow{2}{*}{ (كجم/rז) } & \multirow{2}{*}{ الإتتلجية } \\
\hline & & & & & & r.11 & السنة & $r \ldots v$ & السنة & & \\
\hline \multirow{2}{*}{$v, \varepsilon r$} & \multirow{2}{*}{ v.rq } & \multirow{2}{*}{ r. } & \multirow{2}{*}{$* 0.97$} & \multirow{2}{*}{.$\leqslant 07$} & \multirow{2}{*}{99.00} & $7 . .0$ & للكية & $149 . \varepsilon r$ & للككية & \multirow{2}{*}{ (ألف) } & \multirow{2}{*}{ الإتثاج } \\
\hline & & & & & & $r \ldots \varepsilon$ & السنة & $r .17$ & السنة & & \\
\hline
\end{tabular}

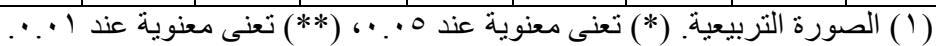

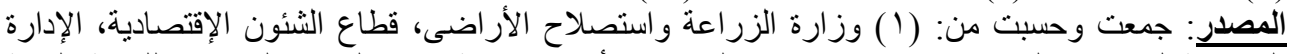

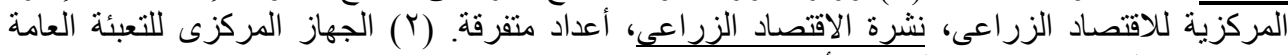

و الإحصاء، الكتاب الإحصائى السنوى، أعداد منفر الإصة الزئ.

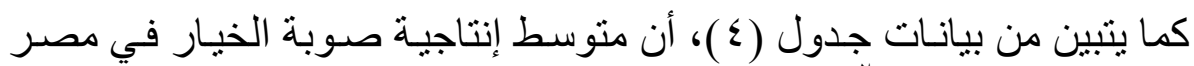

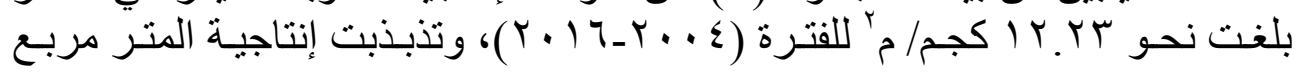




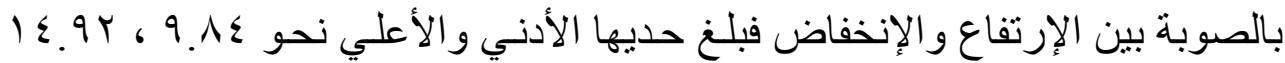

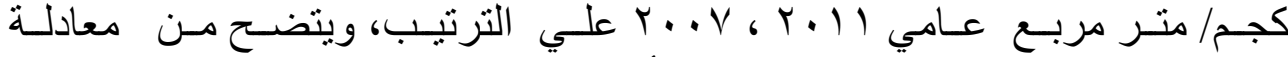

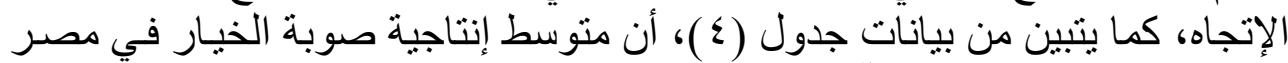

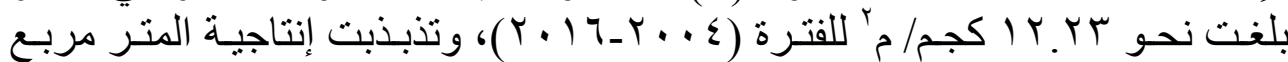

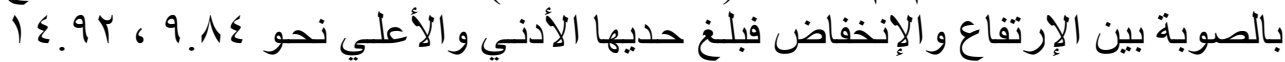

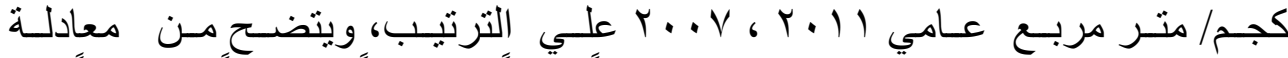

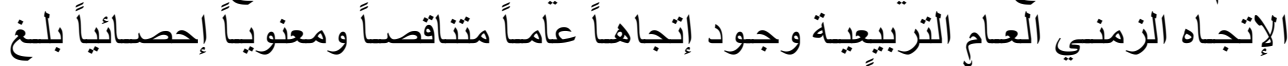

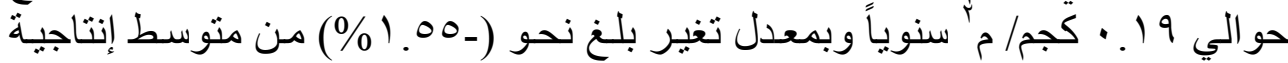

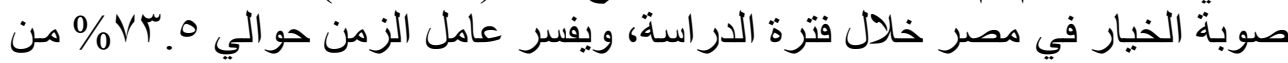

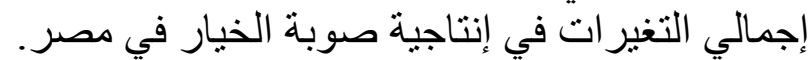

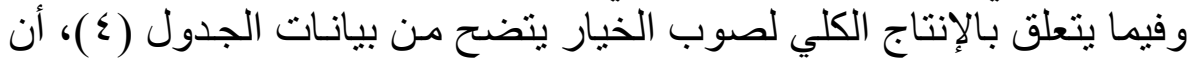

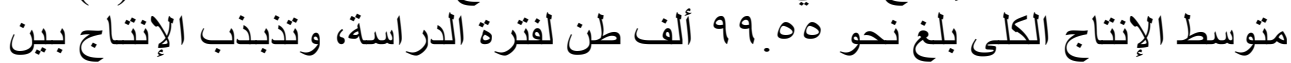

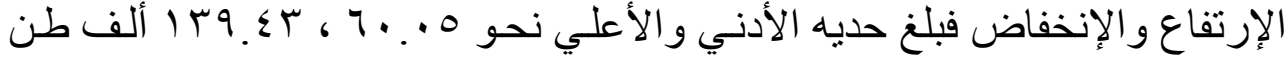

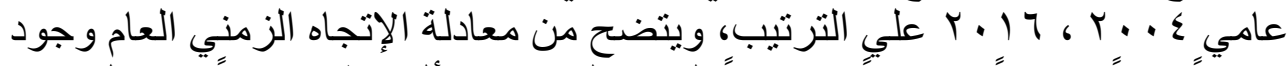

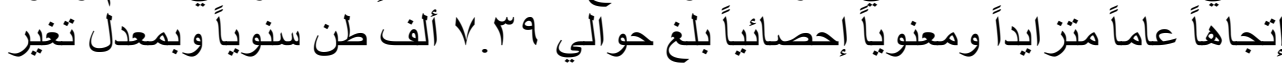

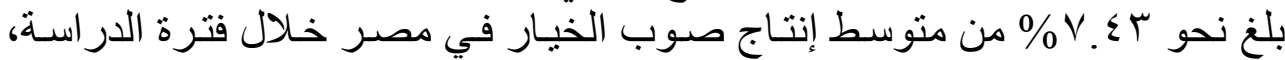

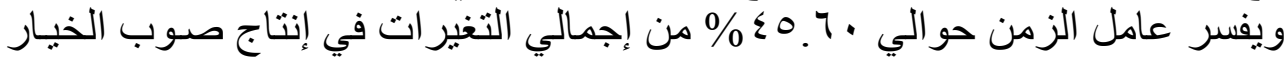

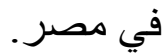

\section{r - محددات الطاقة الإنتاجية لمحصول القلفل بالصوب الزراعية}

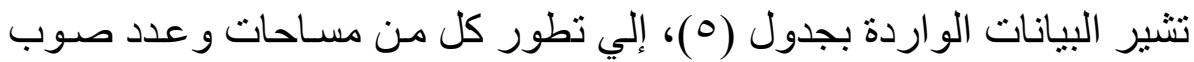

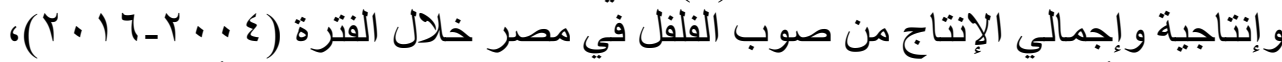

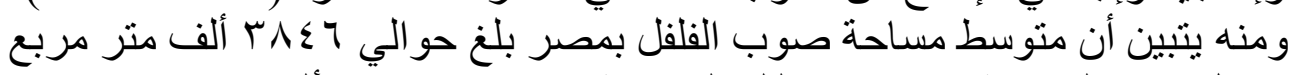

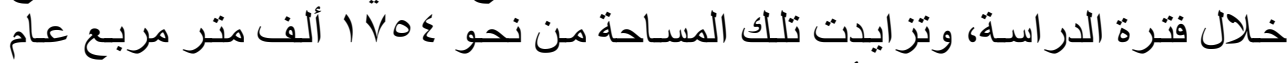

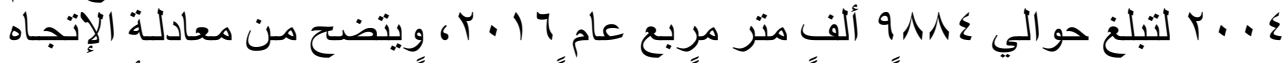

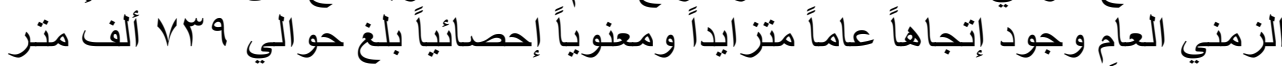

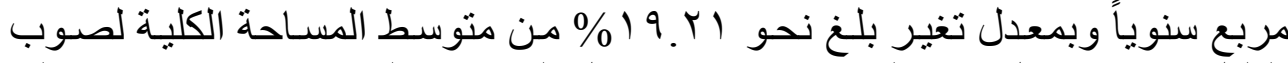

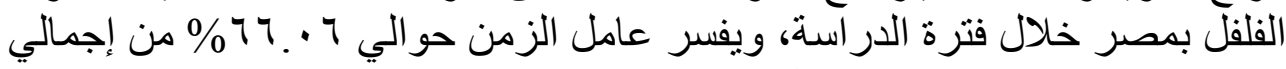

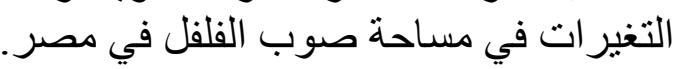

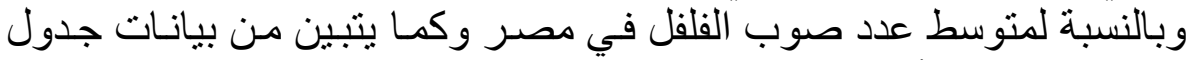

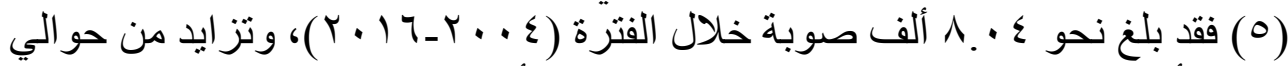

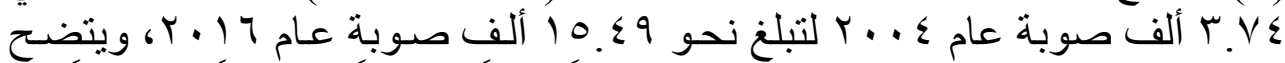

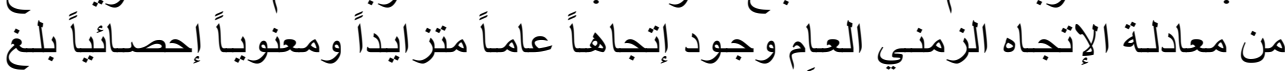

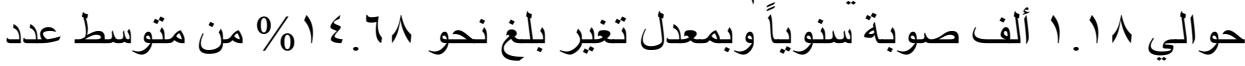


جدول (•): معادلات الاتجاه الزمني العام لتطور أهم المحددات الإنتاجية

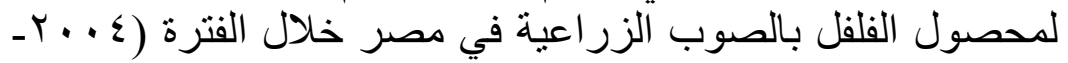

$$
(Y \cdot 17
$$

\begin{tabular}{|c|c|c|c|c|c|c|c|c|c|c|c|}
\hline التغير & التغير & الإختلهـ & $E$ & $\mathrm{D}^{2}$ & متوبط & \multicolumn{2}{|c|}{ الصد الأني } & \multicolumn{2}{|c|}{ الط الأَّصي } & الوحة & الليين \\
\hline \multirow{2}{*}{19.4} & \multirow{2}{*}{$V T q$} & \multirow{2}{*}{$T \leqslant . Y A$} & \multirow{2}{*}{ ש*.T } & \multirow{2}{*}{.97 .7} & \multirow{2}{*}{ TAET } & IVos & المسلحة & $9 M \Lambda \Sigma$ & اللسلحة & \multirow{2}{*}{ (ألف مج) } & \multirow{2}{*}{ المسلحة } \\
\hline & & & & & & $r \ldots \varepsilon$ & السنة & $r .17$ & السنة & & \\
\hline \multirow{2}{*}{$1 \leq .7$} & \multirow{2}{*}{1.11} & \multirow{2}{*}{ \& } & \multirow{2}{*}{ سז. } & \multirow{2}{*}{$\cdot . \wedge 1 \vee \varepsilon$} & \multirow{2}{*}{$\Lambda \cdot \varepsilon$} & $T . V \varepsilon$ & للصوبة & $10 . \leqslant 9$ & للصوبة & \multirow{2}{*}{ صوبة } & \multirow{2}{*}{ الصوب } \\
\hline & & & & & & Y... & السنة & $r .17$ & السنة & & \\
\hline \multirow{2}{*}{$\cdot V^{1 /}$} & \multirow{2}{*}{ ()..$\cdot v_{-}$} & \multirow{2}{*}{$1.0 \mathrm{~V}$} & \multirow{2}{*}{$* * 9 . \cdot 1$} & \multirow{2}{*}{$. \mathrm{VO} . \mathrm{Y}$} & \multirow{2}{*}{9.4} & V.Vo & للانتلجية & $1 . .50$ & للاتتلجية & \multirow{2}{*}{ (كجم/rY) } & \multirow{2}{*}{ الإتتلجية } \\
\hline & & & & & & r.. & السنة & $r \ldots v$ & السنة & & \\
\hline \multirow{3}{*}{ IV.r. } & \multirow{3}{*}{$7 . V$} & \multirow{3}{*}{09.11} & \multirow{3}{*}{ **Ir.AY } & \multirow{3}{*}{$.7 \leqslant 79$} & \multirow{3}{*}{$r \leqslant .9 T$} & $1 \% .7$ & للكبية & דז.17 & للكمبة & \multirow{3}{*}{ (ألف طن) } & \multirow{3}{*}{ الإتناج } \\
\hline & & & & & & T... & السنة & r.17 & السنة & & \\
\hline & & & & & & $r \ldots \varepsilon$ & السنة & $r .17$ & السنة & & \\
\hline
\end{tabular}

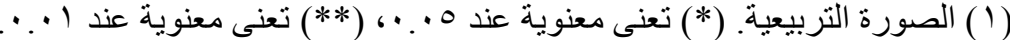

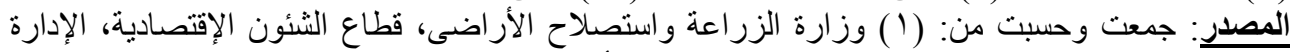

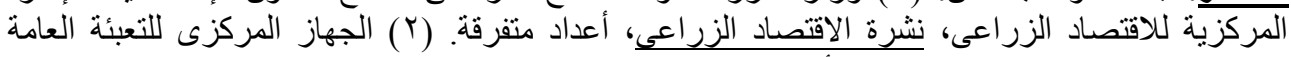
و الإحصاء، الكتاب الإحصائى السنوى، أعداد متفرقة.

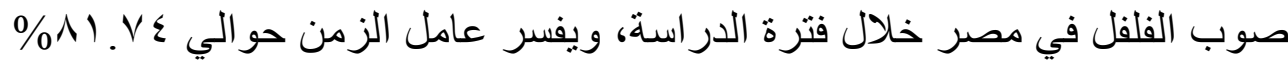

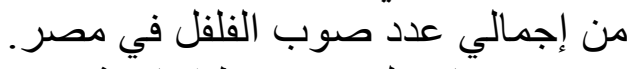

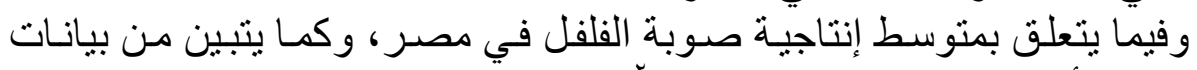

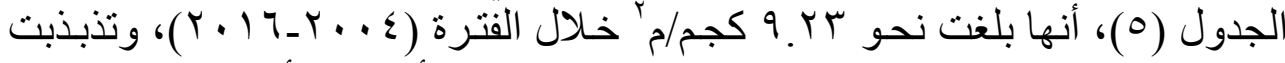

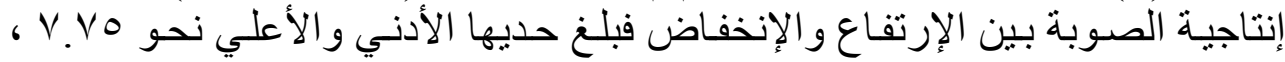

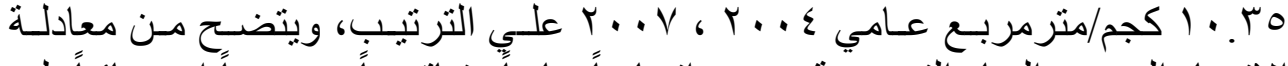

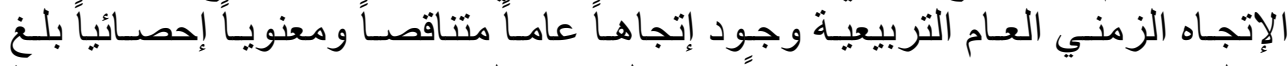

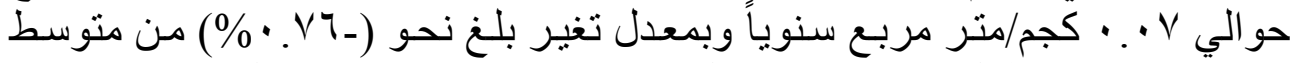

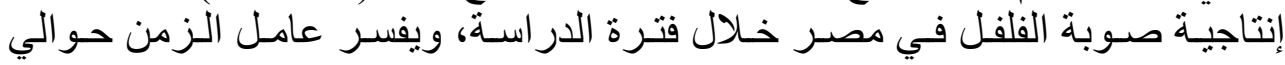

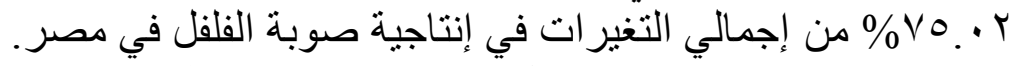

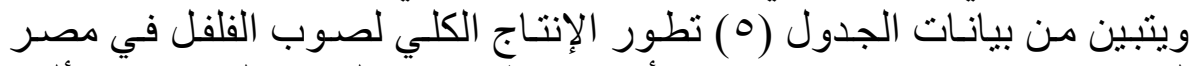

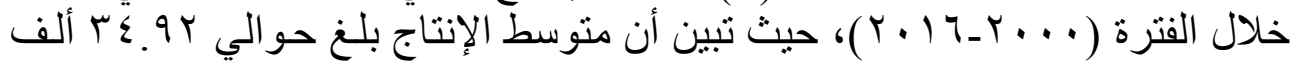

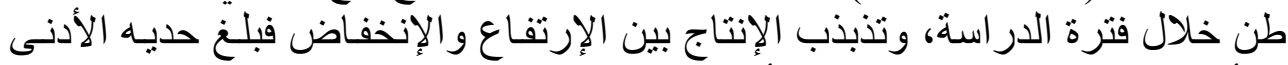

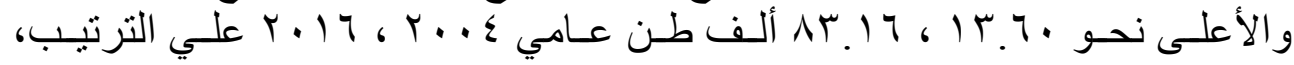




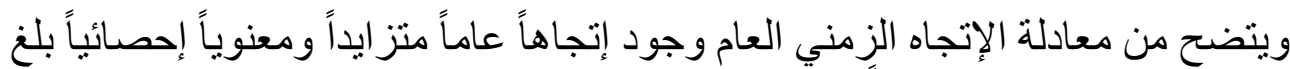

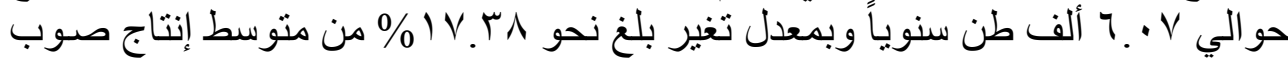

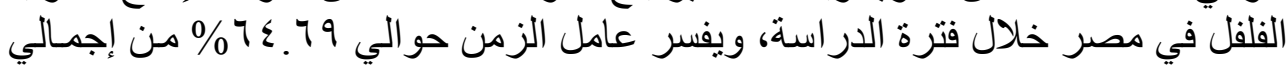
التغير ات في إنتاج صوب خوب الفلفل في مصر.

رابعاً: الكفاعة الإنتاجية النسبية للصوب الزراعية مقارنة بالزراعة التقليدية

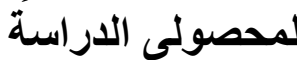

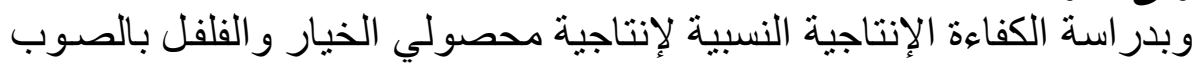

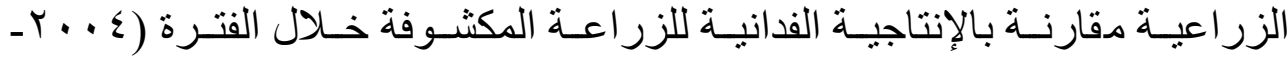

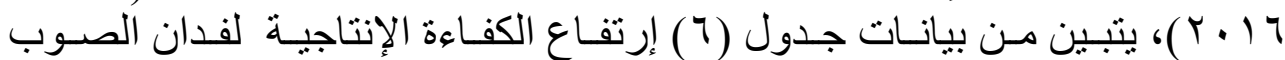

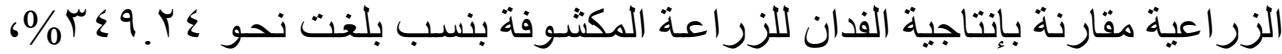

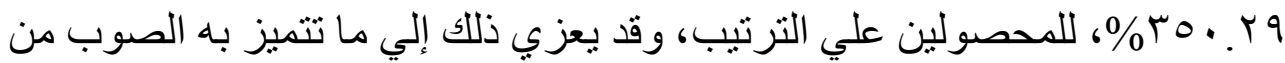

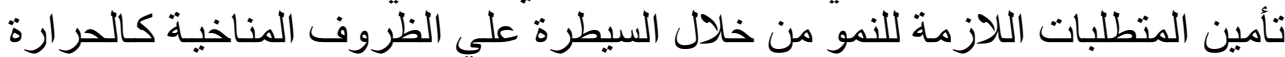

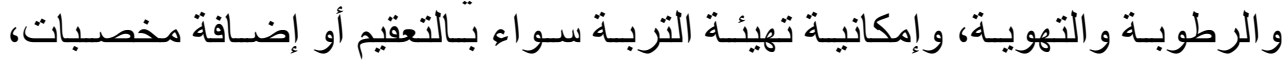

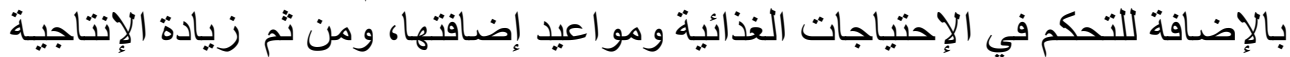

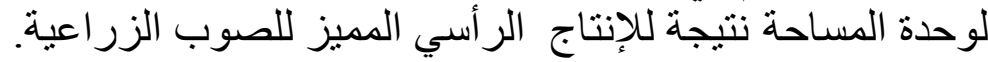

جدول (†): الأهمية النسبية لإنتاجية الصوب الزراعية بالفدان مقارنة بالإنتاجية

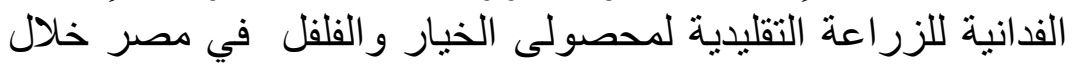

\begin{tabular}{|c|c|c|c|}
\hline الفلفل & الخيار & الوحدة الو & البيان \\
\hline Q.rT & IT.YT & كجم/ar & إنتاجية المتر المريع \\
\hline r.r. & r.q६ & طن/ صوية & إنتاجية الصوية الواحدة \\
\hline$r \leqslant . r \mid$ & rT.rs & طن & إنتاجية فدان زراعة محمية( ) \\
\hline $7.9 \varepsilon$ & 9.49 & طن & الإنتاجية الفدانية زراعة تقليدية \\
\hline ro..rq & $r \leqslant 9 . r \leqslant$ & $\%$ & الكفاءة الإنتاجية النسبية \\
\hline
\end{tabular}


خامساً: إقتصاديات الصوب الزراعية لمحصولى الخيار والفلفل بمنطقة شلاتين

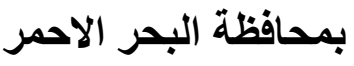

تعتبر الزراعة في البيوت المحمية أحد أهم التقنيات الحديثة لزيادة الإنتاج

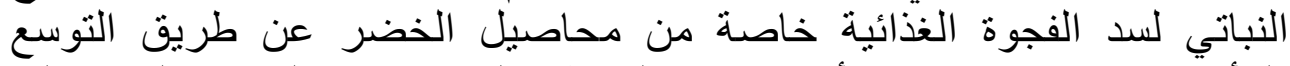

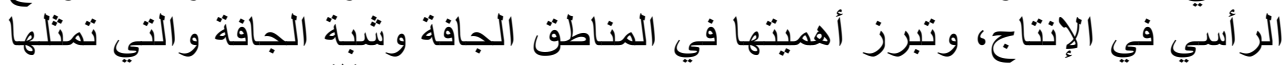

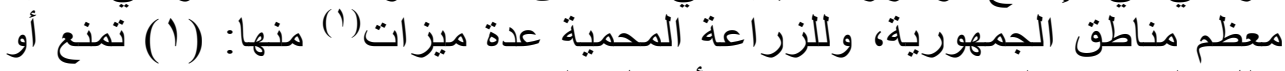

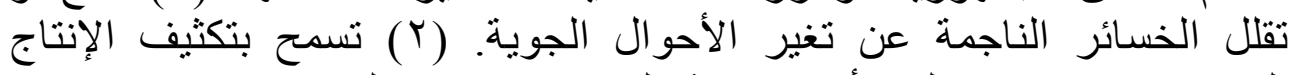

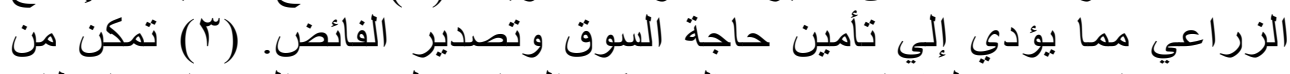

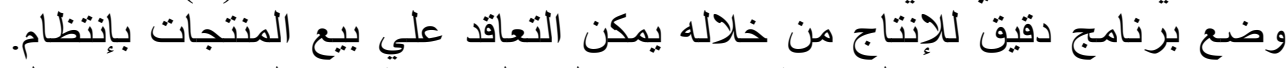

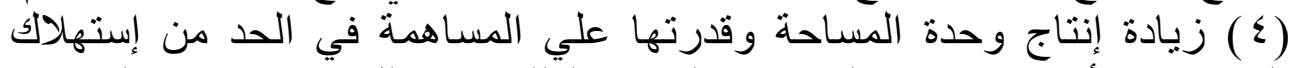

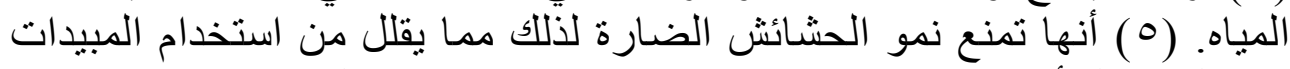

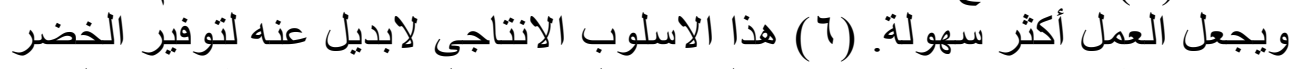

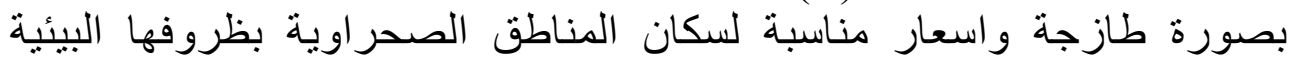
وندرة المياه الصالحة للزر اعة.

\section{1ـ التكاليف الإستثمارية للصوبة الزراعية}

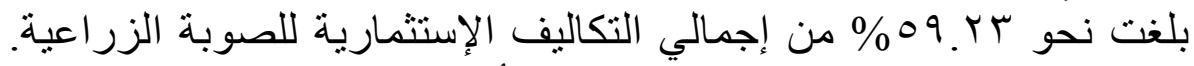

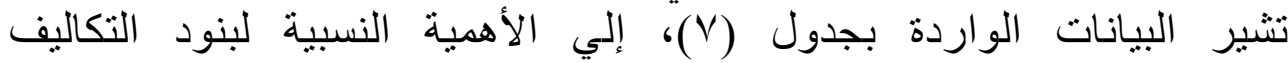

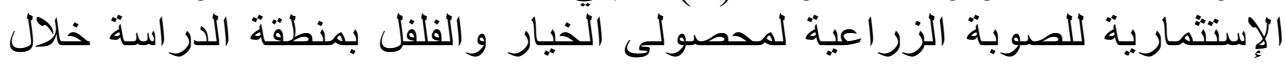

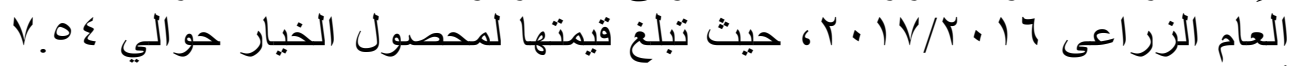

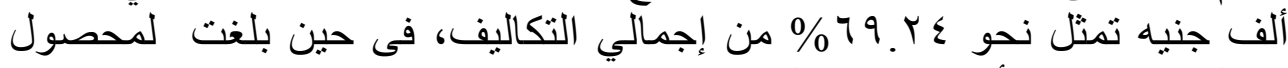

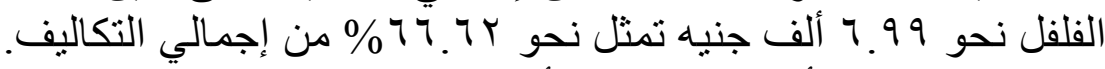

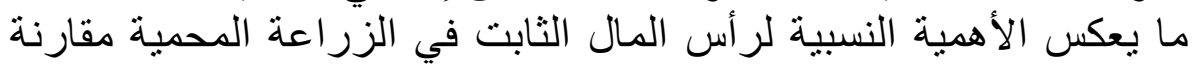

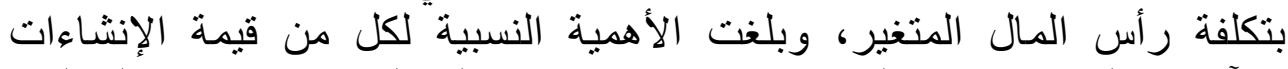

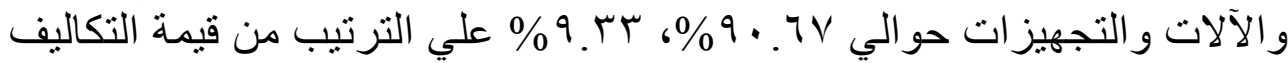

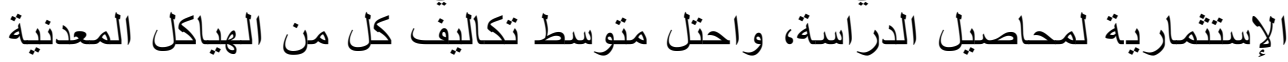

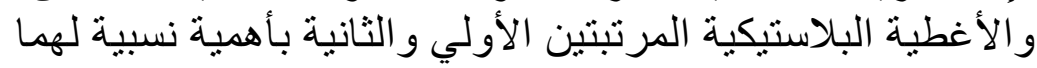

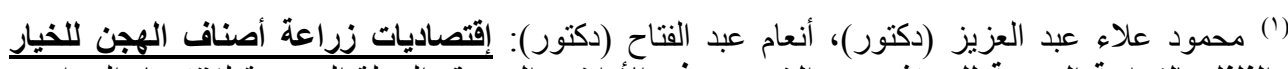

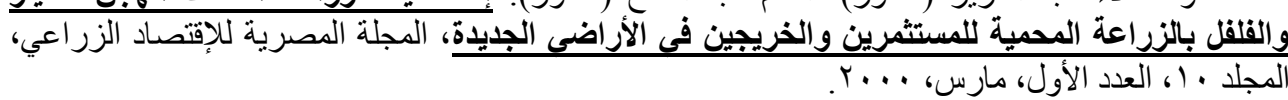




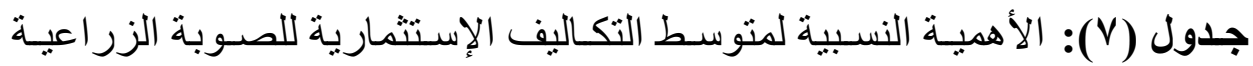

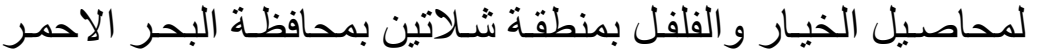

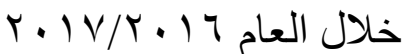

\begin{tabular}{|c|c|c|c|c|c|}
\hline \multicolumn{2}{|c|}{ الفلفل } & \multicolumn{2}{|c|}{ الخيار } & \multirow{2}{*}{ الوحدة الوحة } & \multirow{2}{*}{ البيان البان } \\
\hline$\%$ & القيمة & $\%$ & 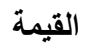 & & \\
\hline $7 . \leqslant$ \& & $\leqslant 0$. & $0.9 \mathrm{~V}$ & $\leq 0$. & جنيه & ايجار الارض \\
\hline$\cdot V r$ & $\circ$. &. .74 & ○. & جنيه & دراسات فنية واقتصادية \\
\hline r. £ & $r \leq$. & $r .11$ & $r \varepsilon$. & جنيه & تجهيز وتهيئة الترية \\
\hline rr.r. & rro. & Y $9 . \wedge \varepsilon$ & rro. & جنيه & هيكل معدنى \\
\hline$r \cdot . V 4$ & $1 \leqslant 0$. & $19 . \mathrm{rr}$ & $1 \leqslant 0$. & جنيه & أغطية بلاستيكية (سيرم ابيض) \\
\hline$\ldots$ & . & ؛.11 & rio & جنيه & كوابل او اسلاك لثد الخيوط \\
\hline$r .01$ & ro. & r.rr & ro. & جنيه & أبواب للصوبة (باب) \\
\hline 7.74 & $\leqslant 70$ & $7.1 \mathrm{~V}$ & $\leq 70$ & جنيه & تكلفة التركيب الكامل للصوية \\
\hline$\cdots$ & . & $r .11$ & $r \leqslant$. & جنيه & خيوط ومدادات \\
\hline Y.AT & r... & r.70 & r. & جنيه & مبانى (مخازن) \\
\hline 7.17 & $\leq r$. & o.v. & $\leq r$. & جنيه & نقل مكونات الصوية \\
\hline \&.70 & rTo & \&.rl & TYO & جنيه & حوض تخزين المياه \\
\hline T. & $r \leqslant$. & r.11 & $r \leqslant$. & جنيه & شبكة الرى للصوية \\
\hline $1 . v r$ & ir. & 1.09 & Ir. & جنيه & حوض تخزين المياه \\
\hline r. & $r \varepsilon$. & $r .11$ & $r \varepsilon$. & جنيه & مضخات المياه \\
\hline.$v r$ & ๑. &. .74 & $\circ$. & جنيه & مواتير الرش والمكافحة \\
\hline צ. & ro & 每 & ro & جنيه & 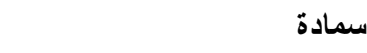 \\
\hline r.A & $r \cdot$. & r.70 & r.. & جنيه & نقل مكونات الصوية \\
\hline $1 \ldots$ & 7910 & $1 \ldots$ & $v_{0} \leq$. & جنيه & جملة التكاليف الاستثمارية \\
\hline
\end{tabular}

المصدر: جمعت وحسبت من بيانات عينة البحث.

r- تكاليف التشغيل للصوبة الزراعية

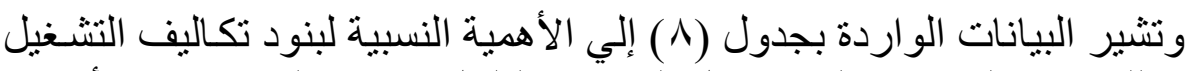

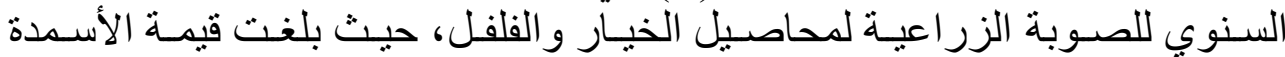

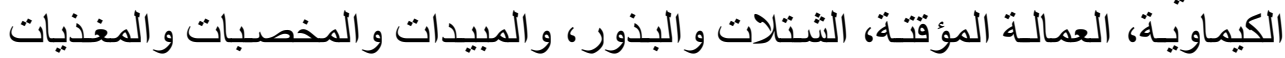
الزر اعية حو الي • 7. ألف جنيه تمثل نحو الب.07\% من إجمالي تكاليف التشغيل 
جدول (^): الأهمية النسبية لمتوسط تكاليف التشغيل السنوي للصوبة الزراعية

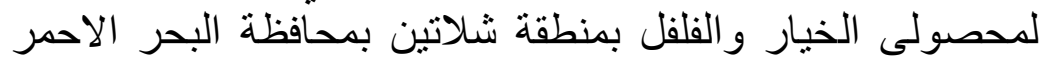

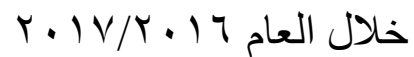

\begin{tabular}{|c|c|c|c|c|c|}
\hline \multicolumn{2}{|c|}{ القلفل القل } & \multicolumn{2}{|c|}{ الغيار } & \multirow{2}{*}{ 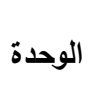 } & \multirow{2}{*}{ 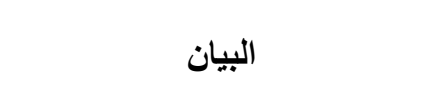 } \\
\hline$\%$ & القيمة & $\%$ & القيمة & & \\
\hline $11 . \leqslant$ & $\leq \ldots$ & Ir. & $\leq 0$. & جنيه & الشتلات والبذور \\
\hline r.1 & vo & $r . r \leq$ & vo & جنيه & تحضين البذور بالمشتل \\
\hline r. I $\leqslant$ & vo & Y.r & vo & جنيه & ميكنة زراعية (خدمة المحصول) \\
\hline V. I $\varepsilon$ & ro. & V. $\leqslant 4$ & ro. & جنيه & الأسمدة العضوية \\
\hline rY.AT & $\wedge .$. & $r \cdot . q$. & $v \ldots$ & جنيه & الأسمدة الكيماوية \\
\hline r.AT & $1 \ldots$ & r.9. & $1 \ldots$ & جنيه & أجور العمالة الدائمة \\
\hline$\varepsilon . q^{2}$ & 10. & r.9. & $1 \cdots$ & جنيه & أجور العمالة المؤقتة \\
\hline$r \leq . r q$ & ^o. & rt.rq & vo. & جنيه & المبيدات والمخصبات والمغنيات \\
\hline$\varepsilon . q^{2}$ & 10. & $\varepsilon . \leqslant \wedge$ & 10. & جنيه & نقل المياه للاحواض \\
\hline$\varepsilon . q^{\prime}$ & 10. & $0.9 \mathrm{~V}$ & r.. & جنيه & تكاليف خدمة وصيانة أدوات ومعدات \\
\hline $1 \ldots$ & ro. & $1 . . \leqslant 0$ & ro. & جنيه & تكاليف إنتقال ونقل خامات ومتطلبات \\
\hline$\varepsilon . \Upsilon^{9}$ & 10. & $\varepsilon . \leqslant \wedge$ & 10. & جنيه & نثريات أخري \\
\hline $1 \ldots$ & ro.. & $1 \ldots$ & 的. & جنيه & جملة التكاليف التشغيل \\
\hline
\end{tabular}

المصدر: جمعت وحسبت من بيانات عينة البحث.

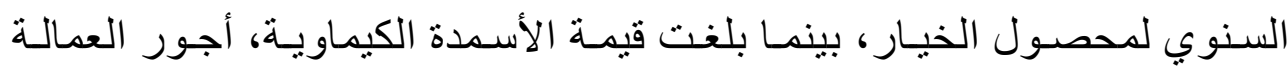

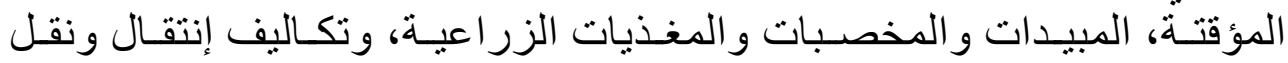

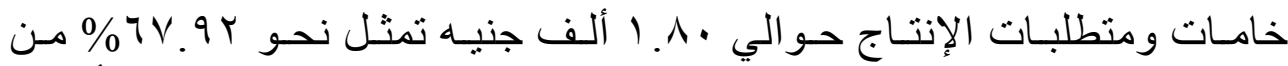

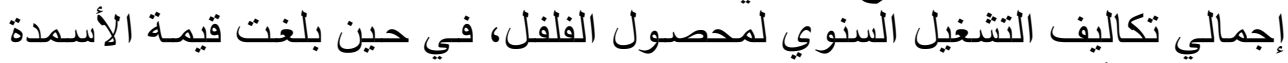

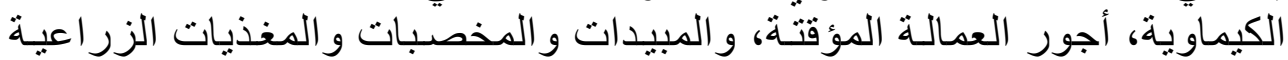

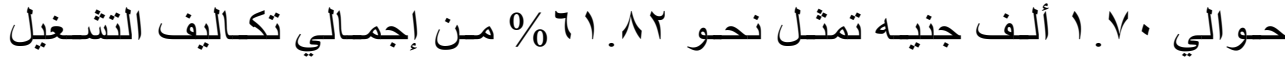
السنوي لمحصول الفلفل. 
r- الإيرادات الكلية للصوية الزراعية

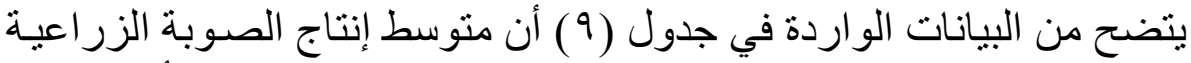

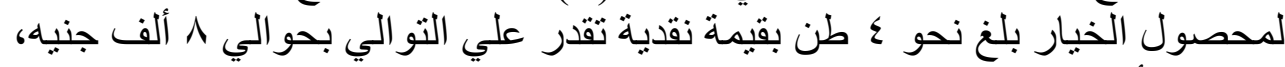

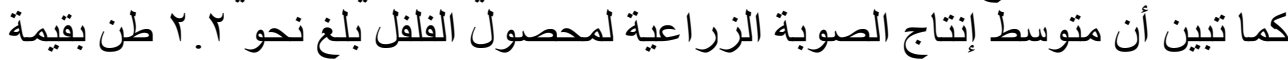

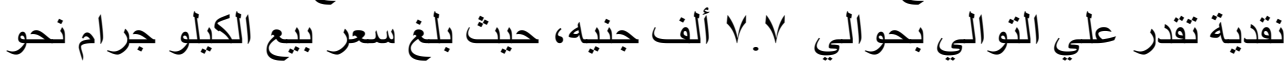

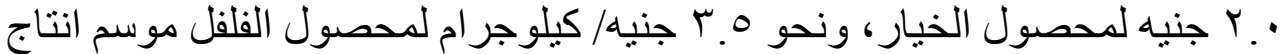

جدول (9): منوسط قيمـة الإنتاج للصـوب الزر اعيـة لمحاصيل الخيـار و الفلفل

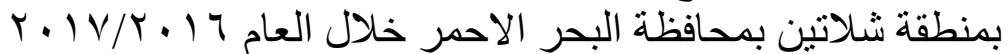

\begin{tabular}{|c|c|c|c|}
\hline الفلقل & الخيار & 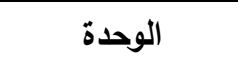 & البيان \\
\hline r. & $\varepsilon$ & (طن/صوبة) & متوسط إنتاج الصوبة \\
\hline T.० & r & (ألف جنيه/طن) & متوسط السعر \\
\hline r. v.. & $\wedge$ & (ألف جنيه/صوبة) & قيمة الإنتاج للصوبة \\
\hline
\end{tabular}

المصدر: جمعت وحسبت من بيانات عينة البحث.

ساداً: التحليل المالي لإنتاج محصولى الدراسة بالصوب الزراعية بمنطقة شلاتين بمحافظة البحر الأحمر

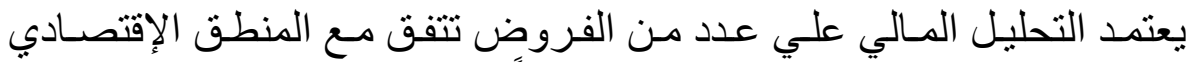

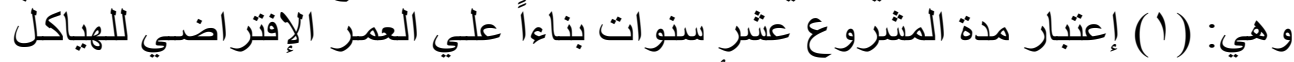

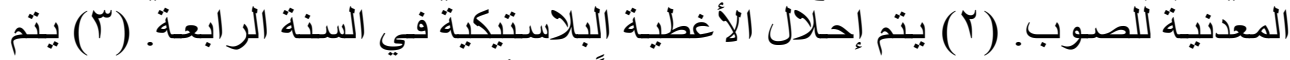

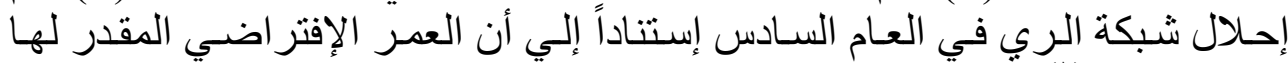

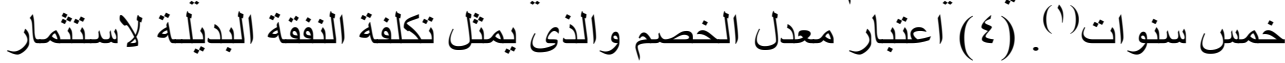

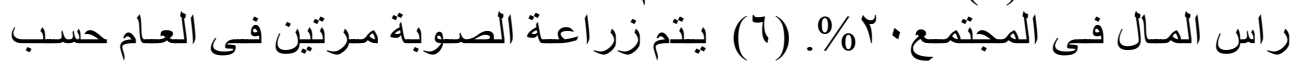
مو اعيد الزر اعة(شتوى، نيلى) بالمنطقة وبتبادل المحصولين مع بعضهم.

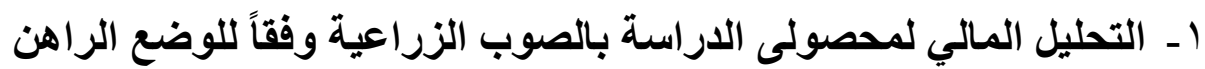

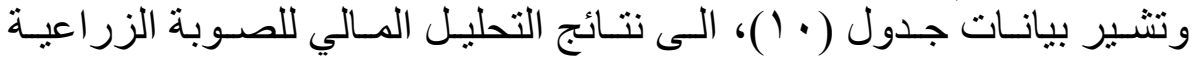

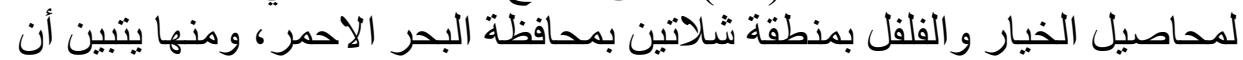


جدول (• (1): نتائج التحليل المـالي للصـوبة الزر اعيـة لمحاصيل الخيـار و الفلفل

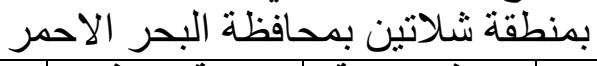

\begin{tabular}{|c|c|c|c|c|c|}
\hline فترة إسترداد & الداخلى (IRR) & نسبة المنافع التكاليف & صافي القيمة ألية & \multicolumn{2}{|c|}{ البيان } \\
\hline (سنة) & $\%$ & (ألَف جنيه) & (ألف جنيه) & الوحدة & \\
\hline 1.0. & $T V$ & $1 . \leqslant 9$. & $9 . \wedge \vee \wedge$ & الخيار & المحصول \\
\hline $1 . \leqslant 0$ & 79 & $1 . \leqslant V$. & q.VIr & القلقل & \\
\hline
\end{tabular}

المصدر: نتائج تحليل برنامج .Cost Ben لبيانات جداول الدر اسة الميدانية.

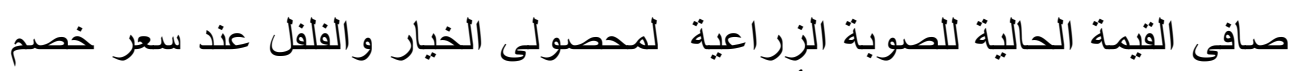

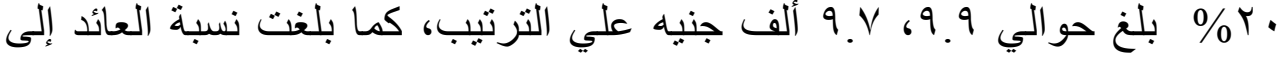

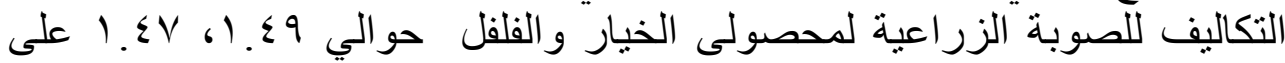

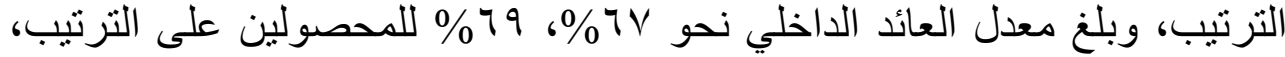

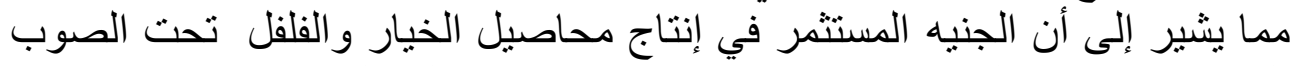

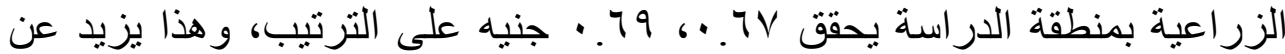

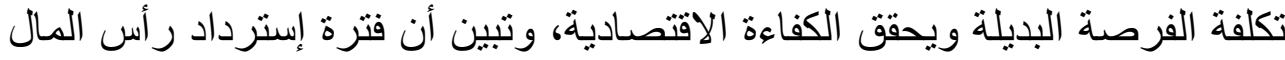

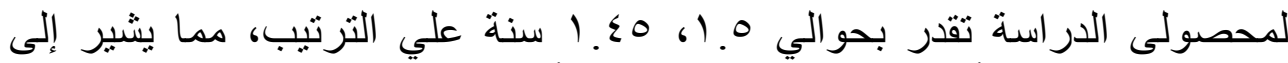

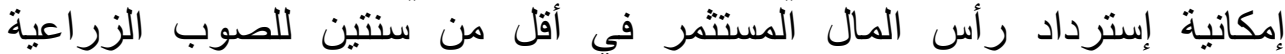

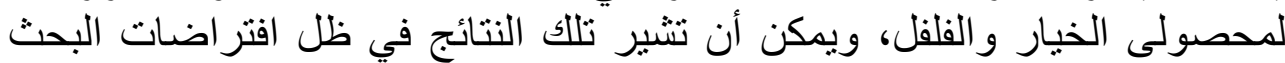

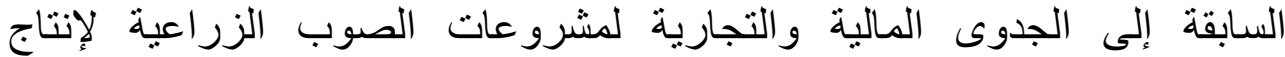
محصولى الخيار و الفلفل بمنطقة الدر اسة.

سابعاً: التحليل المالي لمحصولى الدراسة بالصوب الزراعية وفقاً لتحليل الحساسية

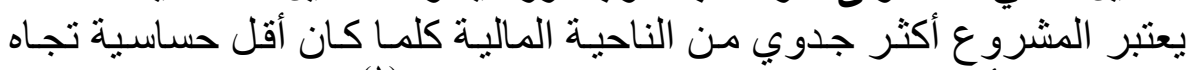

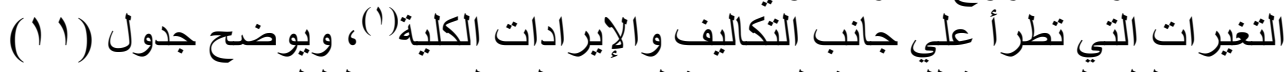

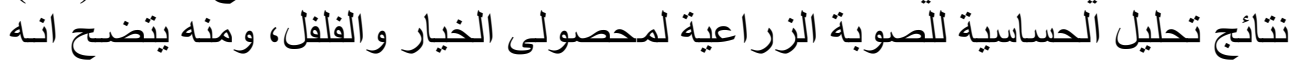

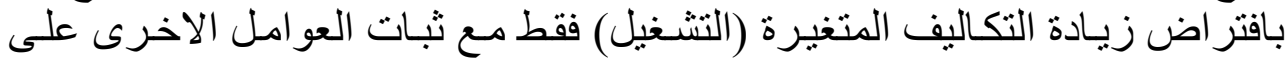

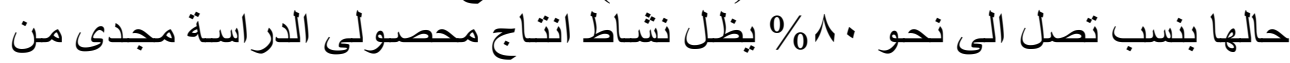

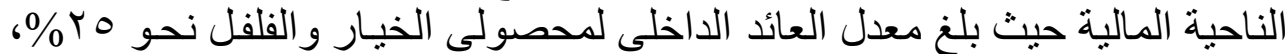

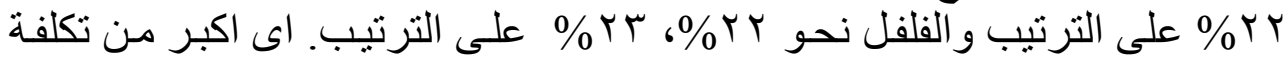

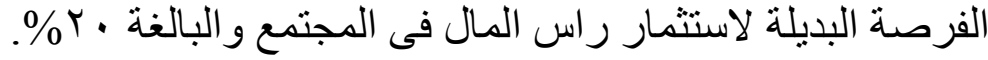

(') Gittinger, J. Price, "Economic Analysis of Agricultural projects", $2^{\text {nd }}$ edition, The johns Hopkins University press, Baltimore and London, 1982. 
جدول (1 1 ): نتائج تحليل الحساسية للصـوبة الزر اعيـة لمحاصيل الخيـار و الفلفل بمنطقة شلاتين بمحافظة البحر الاحمر

\begin{tabular}{|c|c|c|c|c|c|c|c|}
\hline فأسترة & $\begin{array}{l}\text { معدل العائد } \\
\text { الداخلي } \\
\text { (IRR) }\end{array}$ & المنافع إلية & القافية & للإلتماليفة القيمة القية & 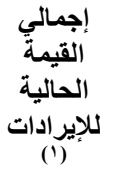 & & البيان \\
\hline (سنة) & $\%$ & (ألف جنيه) & (ألف جنيه) & (ألف جنيه) & (ألف جنيه) & الوحدة & التغيرات \\
\hline $1.9 \varepsilon$. & or & $1 . r v$. & $7.0 . r$ & $r T . V \cdot \varepsilon$ & $r \cdot . r \cdot T$ & الخيار & \multirow{2}{*}{ زيادة تكاليف التشغيل الى · ب\% } \\
\hline 1.94. & or & $1 . r 7$. & 7.110 & $r \varepsilon ., Y l$ & r. r. & الفلفل & \\
\hline r.vq. & דr & $1.1 \%$. & T.ITV & $r v . \cdot v q$ & T.r.r. & الخيار & \multirow{2}{*}{ زيادة تكاليف التشغيل الى †\%\% } \\
\hline r.q.. & re & $1.1 \ldots$ & r. $70 \wedge$ & $Y V .0 \leqslant q$ & ז.r. & الفلفل & \\
\hline$\varepsilon .7$. & ro & $1 . T$. &.$\wedge \vee \neg$ & וrr. & $r \cdot . r \cdot T$ & الخيار & \multirow{2}{*}{ زيادة تكاليف التشغيل الى ^\% } \\
\hline$\varepsilon .7 \ldots$ & rr & 1.1 & $\cdot r \cdot T$ & rq. $9 \ldots$ & $r \cdot r \cdot r$ & الفلفل & \\
\hline$\varepsilon . \wedge \wedge$. & $r$. & $1 \ldots$ & $\cdot \wedge \vee \top$ & וזr. & $r \cdot r \cdot T$ & الخيار & \multirow{2}{*}{ ن برية التعادل لزيادة تكاليف التشغيل = } \\
\hline$\varepsilon .9 \ldots$ & $r$. & $1 \ldots$ & $\cdot r .$. & • & $r \cdot r \cdot r$ & الفلفل & \\
\hline Y.TV. & rV & 1.19. & $r . \wedge r v$ & $r \cdot r$ r & $r \leq 170$ & الخيار & \multirow{2}{*}{ انخفاض الايرادات · r \% } \\
\hline Y.7. & rᄉ & 1.11. & r.TVI & $r \cdot . \leq 9 \leq$ & $r \leqslant .170$ & الفلفل & \\
\hline$\Sigma . r Y$. & $r \leq$ & $1 . \varepsilon$. & .117 & $r \cdot r$ r & $r_{1} .1 \leqslant 0$ & الخيار & \multirow{2}{*}{ انخفاض الايرادات · ب\% } \\
\hline$\varepsilon . r$. & r & $1 . r$. & .70 & $r . . \leq q \leq$ & $r_{1} .1 \leq \varepsilon$ & الفلفل & \\
\hline 0.11. & $r$. & $1 \ldots$ & $\because \cdot \wedge \wedge$ & $r \cdot$ r r & $r \cdot . r \Lambda$ & الخيار & نقطة التعادل لانخفاض الاير ادات= • ؛\% \\
\hline$\varepsilon .90$ & r. & $1 . \cdots$ & $\because \leqslant 0$ & $r \cdot . \leq 9 \leq$ & $r \cdot .0 \leqslant$. & 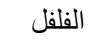 & نقطة التعادل لانخفاض الايرادات ؟ ؛ \\
\hline r..$\varepsilon$ & rV & $1 . v \cdot$ & 1.017 & r. OVq & $r \leqslant .170$ & الخيار & زيادة التكاليف وانخفاض العائد معاً . ro \\
\hline$r . \vee\urcorner$. & rV & 1.7. & 1.419 & $r Y . \wedge \leqslant 7$ & $r \varepsilon .177$ & 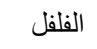 & زيادة التكاليف وانخفاض العائد معاً · r \% \\
\hline$\varepsilon . \wedge \wedge$ & r. & $1 \ldots$ & $\because \cdot 1 \mathrm{~V}$ & rr.q人q & rT.90V & الخيار & العائد معاً ب التعادل لزيادة التكاليف وانخفاض \\
\hline$\varepsilon .94$. & r. & $1, \cdots$ & $\because \varepsilon \wedge$. & rT.1.99 & rr.roq & 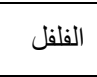 & العائدة معاً بـ التعادل لزيادة التكاليف وانخفاض \\
\hline
\end{tabular}

المصدر: نتائج تحليل برنامج .Cost Ben' لبيانات جداول الدراسة الميدانية.

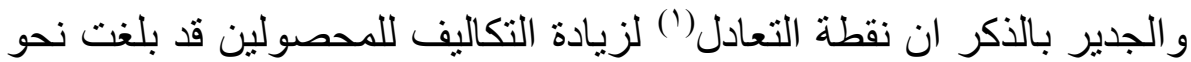

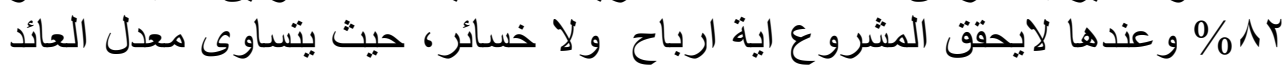
الاخلى مع تكلفة الفرصة البديلة.

(') Brown Maxwell L, "Farm Budgets: From Farm Income Analysis to Agricultural projects Analysis" Baltimore, Md, Johns Hopkins University Press, 1979. 


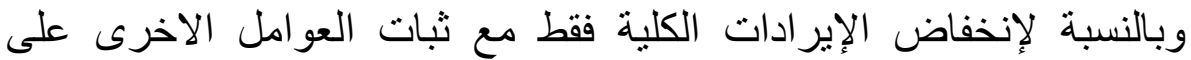

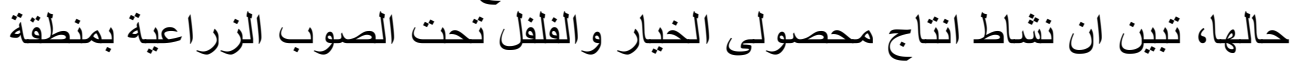

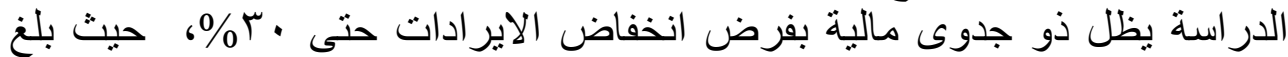

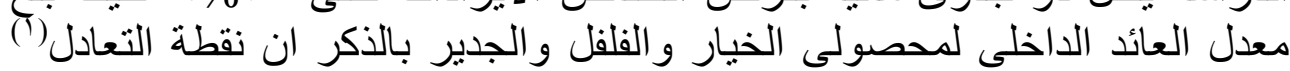

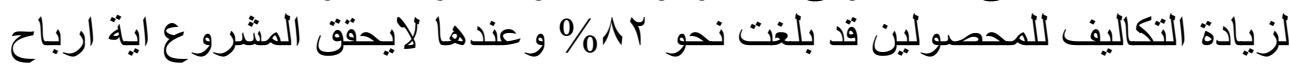

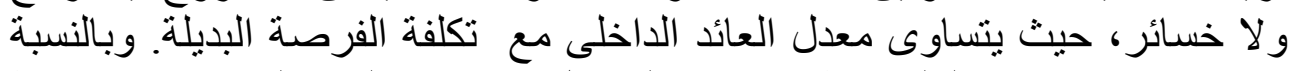

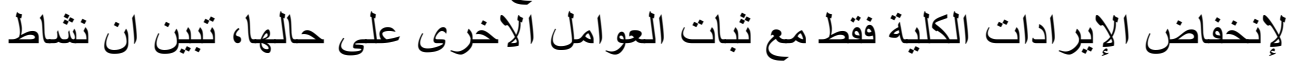

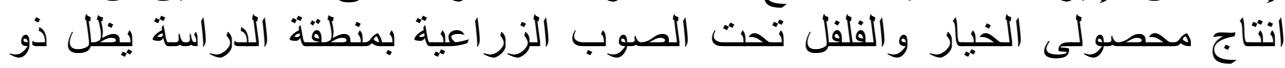

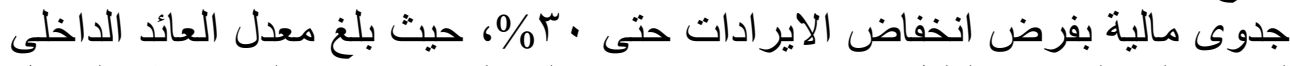

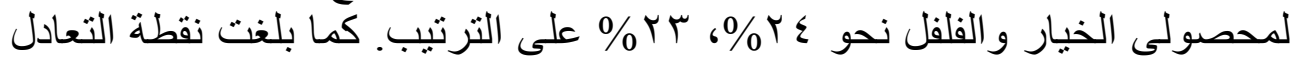

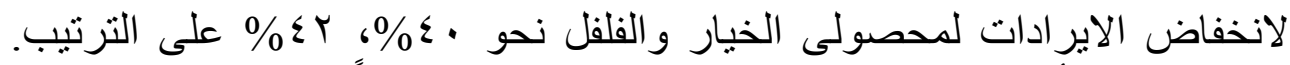

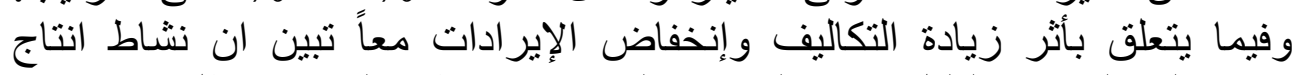

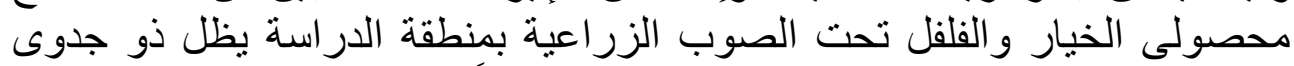

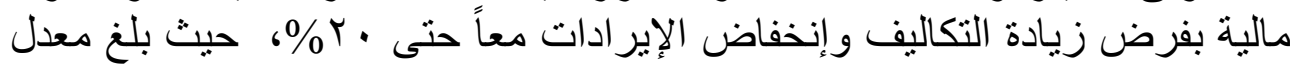

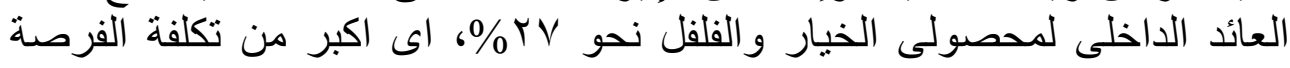

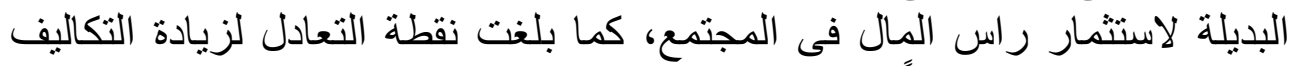

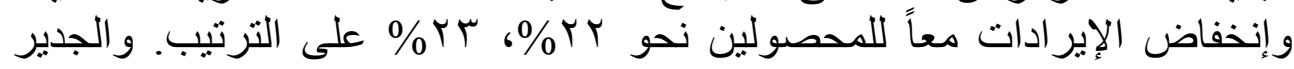

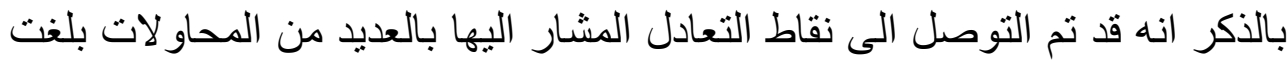
اكثر من • ب محاوله لكل حالة من الحالات سالفة الذكر بطريقة اليه.

\section{المشاكل التي تواجه إنتاج الخضر بالصوب الزراعية بمنطقة شلاتين بمحافظة}

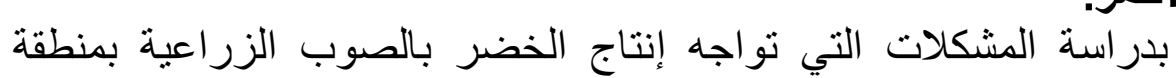

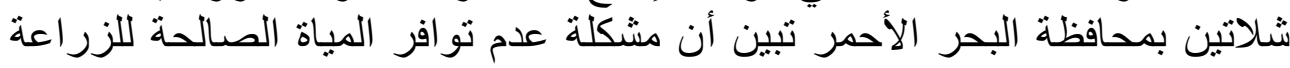

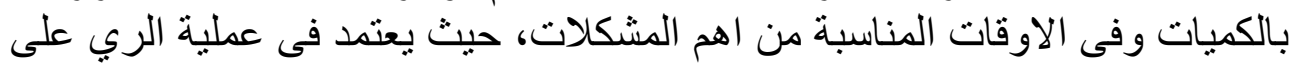

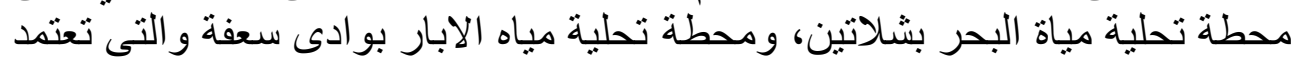

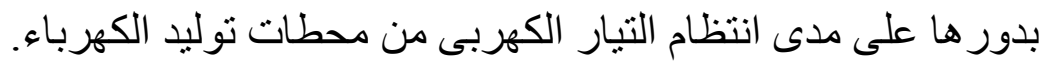

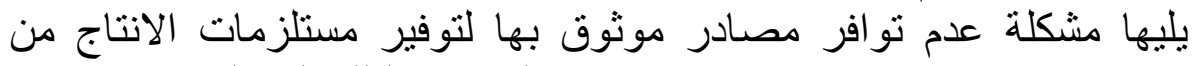

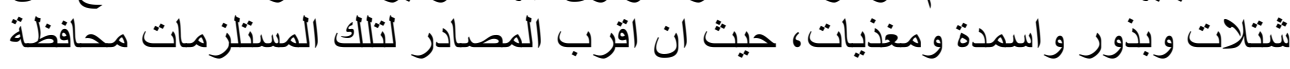

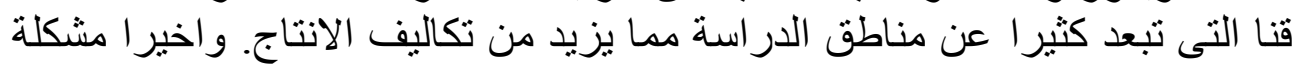

(') Brown Maxwell L, "Farm Budgets: From Farm Income Analysis to Agricultural projects Analysis" Baltimore, Md, Johns Hopkins University Press, 1979. 
ضعف التربة الزراعية وافتقارها للعناصر الغذائية الضرورية لانتاج الخضر

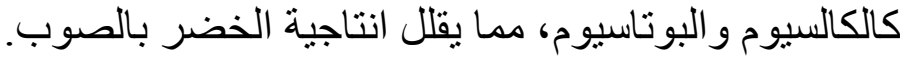

التوصيـــات

\section{وفى ظل النتائج البحثية المتحصل عليها يوصى البحث بما يلي:}

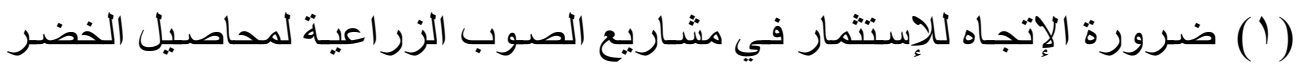

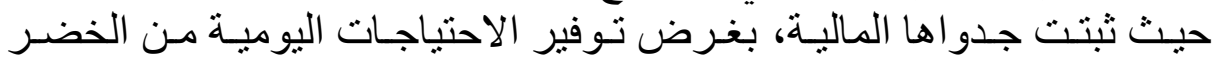

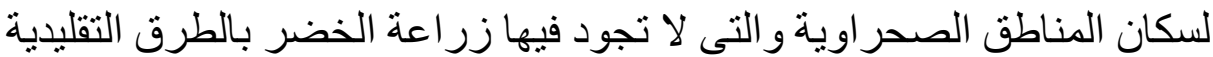

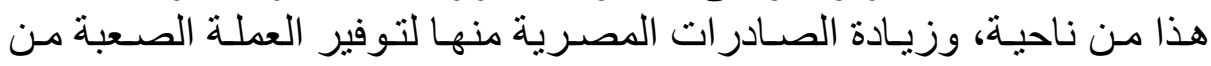

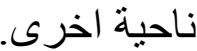
إجر اء المزيد من الدر اسات و البحوث الفنية (تربة، مياه) و الإقتصادية لتحسين

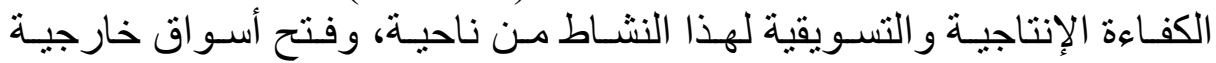

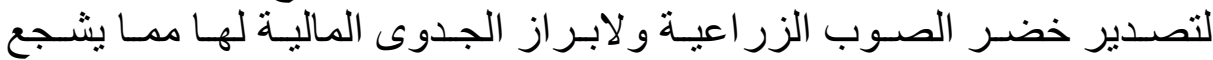

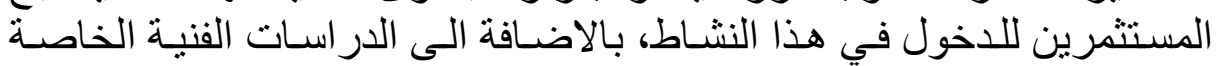

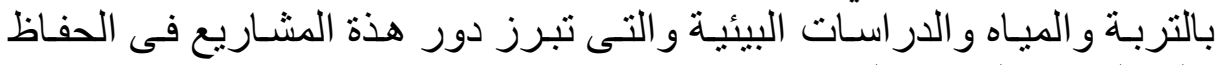
على الصحة العامة و البيئة.

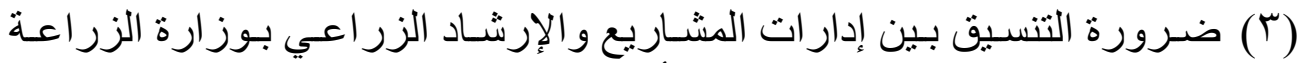

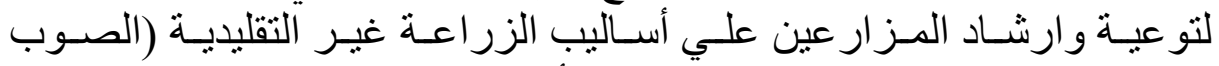
الزر اعية) وتو عيتهم بدور هذه المشاريع و أهميتها.

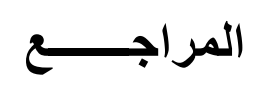

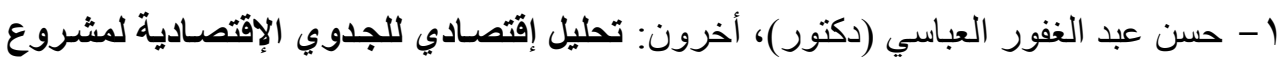

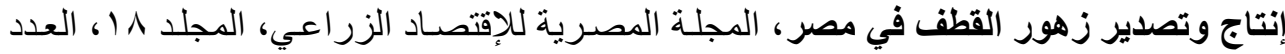

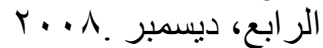

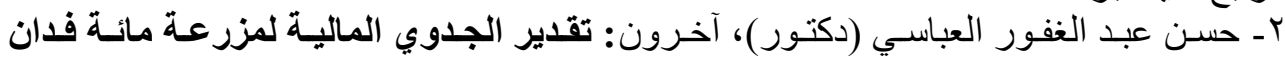

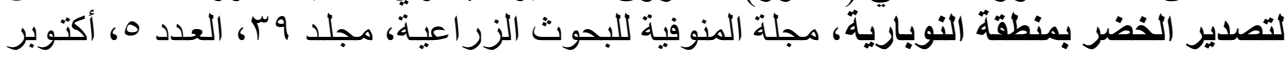
$r+1 \varepsilon$ rا- سمبر عطية محمد عر ام (دكتور)، إبر اهيم حسن إبر اهيم كريم (دكتور ): دراسـة إقتصـادية

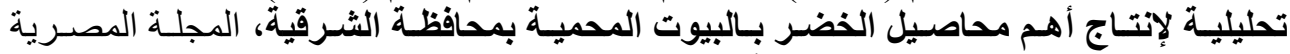

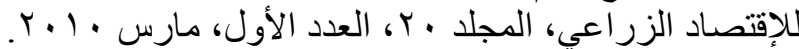

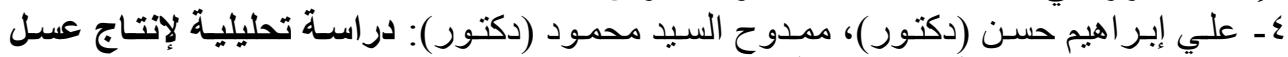

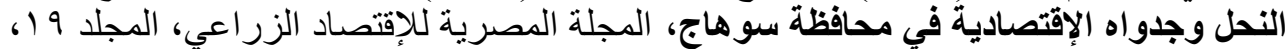
العدد الثاني، يو نيو .9... 


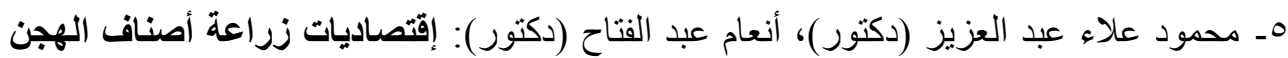

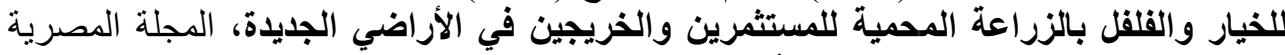

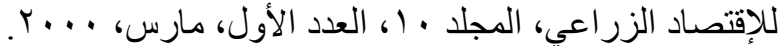

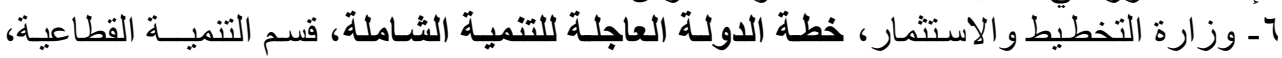

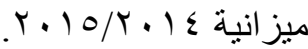

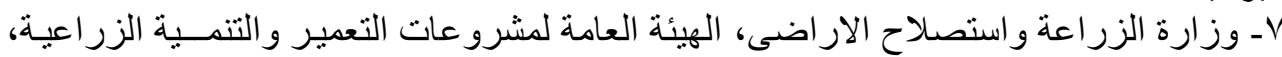

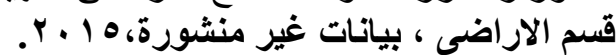

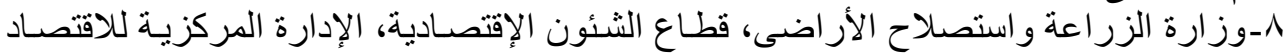

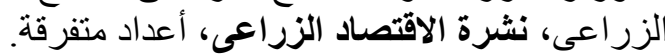

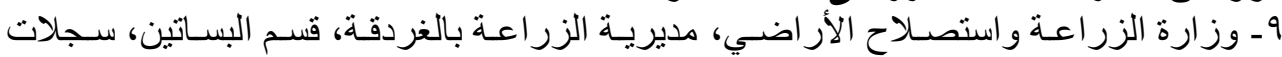

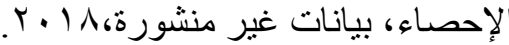

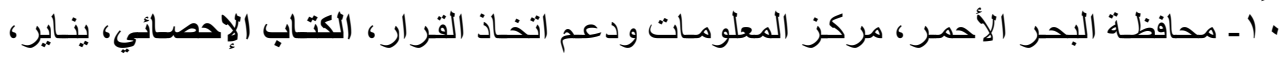

11- Gittinger, J. Price, "Economic Analysis of Agricultural projects", 2nd edition, The johns Hopkins University press, Baltimore and London, 1982.

12-Brown Maxwell L, "Farm Budgets: From Farm Income Analysis to Agricultural projects Analysis" Baltimore, Md, Johns Hopkins University Press, 1979.

\section{AN ECONOMIC SYUDY FOR VEGETABLES PRODUCTION IN GREENHOUSES UNDER DESERT CONDITIONS (Case study: Shalateen Area, Red Sea Governorate)}

Mohamed Ali Abo El Naga and Nadia Mahmoud Mahde

Department of Economic Studies, Division of Economic and Social Studies, Desert Research Center., Egypt.

\section{ABSTARCT}

The main objective of this research is the study of the financial analysis of greenhouses (Cucumber \& Pepper) in Red Sea Governorate. The benefits of the greenhouses, realization possibility of the economic efficiency and the ability of the greenhouses in facing the changes in returns and costs were studied. 
The research is based on the descriptive and quantitative analysis methods to explain and analysis the different theoretical aspects of the study. The cost Ben program has been used to evaluate the benefits of these farms. The study has been depended on primary data obtained from a survey of 16 greenhouses during 2016/2017.

The main results of the research are:

(1) Investment in greenhouses (Cucumber \& Pepper) production is profitable enterprises based on the calculated financial analysis criteria.

(2) Ability the increasing of greenhouses in facing changes in returns and costs according to the sensitivity analysis.

The study have suggested some recommendations to improve greenhouses production.

Keywords: Vegetables, production, greenhouses, Red Sea Governorate 